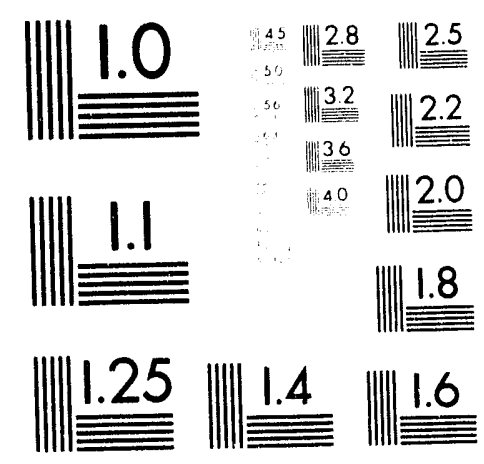



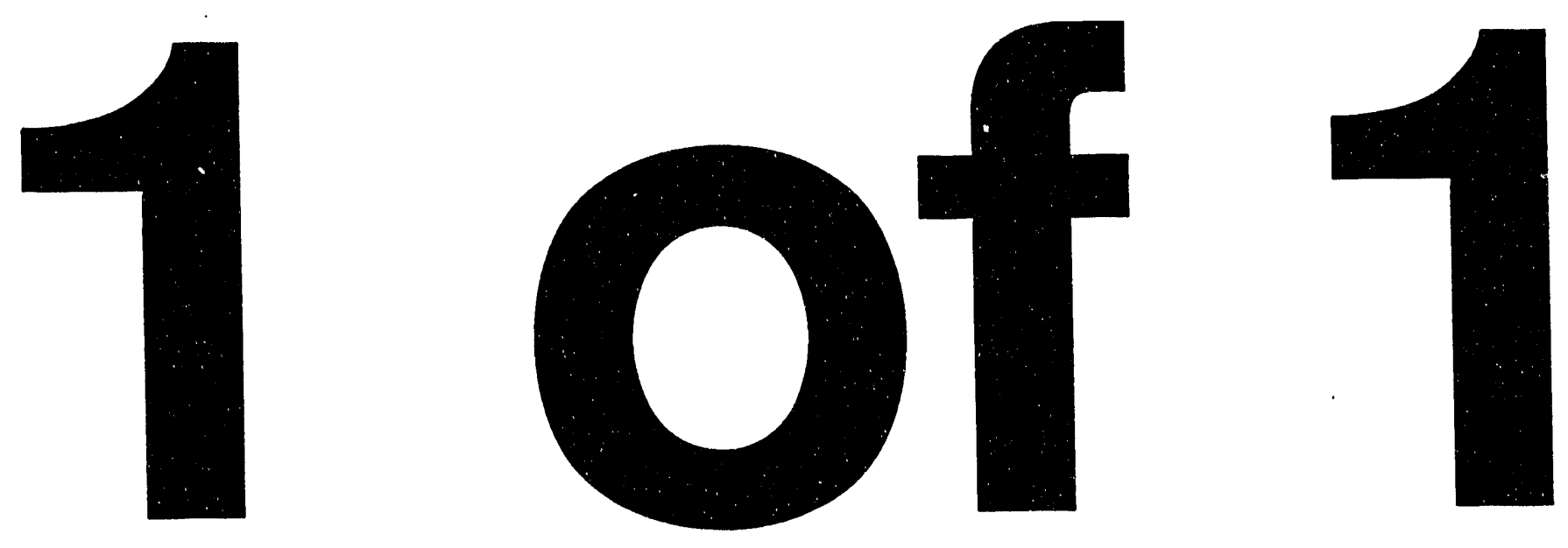
SAND93-1696

Distribution

Unlimited Release

Category UC-906

Printed August 1993

\section{Evaluation of the Deployable Seismic Verification System at the}

Pinedale Seismic Research Facility

D. B. Carr

Seismic Verification Technology Department 9236

Sandia National Laboratories/New Mexico

Albuquerque, New Mexico 87185 


\section{Acknowledgment}

The author thanks Bobby Corbell for his collaboration on this report. Also a special thanks to Monica Carriaga for retrieving all the data, sometimes not an easy thing to do. Bobby Corbell, Preston Herrington and Jim Walkup gave valuable feedback that improved this report. This work was performed at Sandia National Laboratories supported by the U. S. Departınent of Energy under contract DE-AC(04-76DP00789. 


\section{Contents}

Section

Page

Executive Summary.

vii

Acronyms and Abbreviations..................................................... xi

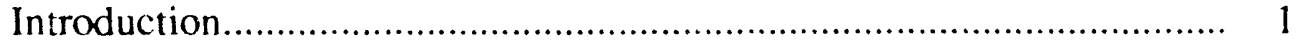

System Description.................................................................. 1

Site Description.................................................................... 3

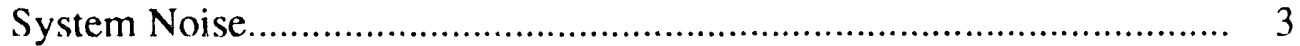

Meteorological Phenomena......................................................... 7

Seismic Response .................................................................... 10

Data Processing ................................................................. 11

Amplitude-Magnitude Relationship........................................ 14

Backazimuth Estimation...................................................... 14

Overlapping Frequencies ................................................... 18

Importance of Broadband Recording ...................................... 18

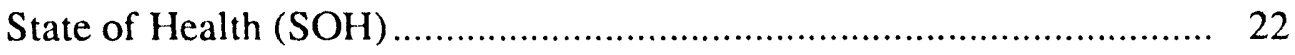

Operational Characteristics ................................................... 25

References................................................................................. 25

\section{Figures}

$\begin{array}{ll}\text { Figure } & \text { Page }\end{array}$

1 The different components of DSVS ............................................ 2

2 Map showing location of PSRF................................................. 3

3 Median velocity spectra for the HF band .................................. 4

4 Median velocity spectra for the IP band .................................. 5

5 Median velocity spectra for the LP band .................................. 6

6 Median velocity spectra for different values of average wind speed ......................................................................... 8

7 Median velocity spectra for different seasons on the HF band ....... 8

8 Median velocity spectra for different seasons on the IP band ....... 9

9 Median velocity spectra for different seasons on the LP band ...... 9

10 Map of events used to study the seismic response of DSVS ........ 11

11 Traces from a local magnitude 3.0 earthquake $236 \mathrm{~km}$ east of PSRF......................................................................... 12 


\section{Figures (cont)}

Figure Page

12 Traces from $a m_{b}=6.0$ earthquake $1262 \mathrm{~km}$ west of PSRF .......... 13

13 Traces from a $m_{b}=4.3$ earthquake $12(x) \mathrm{km}$ west of PSRF.......... 15

14 NEIS $m_{b}$ magnitudes compared to magnitudes calculated

from Evernden's WUS magnitude calculation..................... 16

15 Range of errors in backazimuth using (a) Magotra et al. and

(b) Roberts et al ......................................................... 17

16 Traces from an NTS explosion on the LP and filtered IP bands ..... 19

17 Traces from an earthquake $625 \mathrm{~km}$ SSW of PSRF on the L.P and filtered IP band .......................................................... 20

18 Frequency where $\mathrm{SNR}=0$ versus distance......................... 21

19 Frequency where SNR = ) versus azimuth.............................. 22

\section{Tables}

Table

Page

1 Breakdown of seasons used for seasonal variation

7

2 Filters, time spans, and methods used to calculate backazimuths 16

3 Precision of backazimuth estimates .................................... 18

4 State of health information ............................................. 23 


\section{Executive Summary}

The intent of this report is to examine the performance of the Deployable Seismic Verification System (DSVS) developed by the Department of Energy (DOE) through its national laboratories to support monitoring of underground nuclear test treaties. A DSVS was installed at the Pinedale Seismic Research Facility (PSRF) near Boulder, Wyoming during 1991 and 1992. This includes a description of the system and the deployment site (pp 1-3).

We studied system performance by looking at four areas: system noise, seismic response, state of health (SOH) and operational capabilities. System noise (pp 3-7) was studied by comparing velocity spectra to the USGS-Peterson low noise model and the self noise of the instrumentation. A median spectrum on each axis was calculated in each band. We found that the amplitudes of the median spectra are similar to the USGS-Peterson low noise model at frequencies below $0.15 \mathrm{~Hz}$ (Fig. 4). Above $0.15 \mathrm{~Hz}$ the median spectra are below the low noise model except between 3 and $6 \mathrm{~Hz}$ (Figs. 3, 4). The self noise of the system falls below the medians and is not a major component of the background noise. These results indicate that the transfer functions for the seismometers are correct. The overlapping frequency bands have similar responses (Figs. 3,4 and 5).

The affect of wind and seasonal variations on the background noise was also studied (pp 7-10). The effect of increasing wind velocity was only seen on the HF band (Fig. 6) and resulted in the level of the entire spectrum increasing as the noise increased. Peaks around $10,26,38$ and $48 \mathrm{~Hz}$ also increase with increasing wind and we believe they are due to the antenna or fence resonating in the wind. Figures 7,8 and 9 show the seasonal variation in background noise. The median noise in winter is 2 to $14 \mathrm{~dB}$ higher than the median noise in summer at frequencies under $0.9 \mathrm{~Hz}$ (Figs. 8, 9), while at frequencies over $1.0 \mathrm{~Hz}$ the lowest median noise is in the winter and the highest is in the summer (Figs. 7, 8). We believe the higher noise levels in the summer in the HF band are the result of higher wind velocities in the summer at PSRF.

We studied the seismic response of DSVS using a database of 91 events occurring within $20^{\circ}$ of PSRF that had known locations and magnitudes in the NEIS PDE bulletin (pp 10-22). $P$ arrivals were seen for 75 of the 91 events; most events not recorded at PSRF were small magnitude events over $900 \mathrm{~km}$ away. $\mathrm{L}_{\mathrm{g}}$-waves were seen for almost all the events. Examples of seismic events recorded on DSVS at PSRF are in Figures 11 and 12. Over half of the recorded events were not detected on the HF band until the traces were low passed filtered under $4 \mathrm{~Hz}$ (Fig. 13). High pass filtering on the IP band to get rid of the low frequency noise was important to get good arrival times for some events. The local noise obscures the signal for some small magnitude or large distance events since the instrument has such a wide bandwidth.

Magnitudes were calculated using Evernden's WUS magnitude formula and the largest 0 -peak amplitude in the first 10 seconds of the $P$ wave for large $m_{b}$ events. When compared to the NEIS magnitudes the result is a least squares fit to a line with the slope of 1.1 (Fig. 14), indicating the transfer function to convert to displacement is correct.

Backazimuth calculations for 70 of the events indicate that to get good estimates the HF band needs to be filtered between 0.5 and $2.0 \mathrm{~Hz}$. The precision of the estimates is $24^{\circ}$ 
which is not as good as the precision of estimates found for the RSTN stations and Norwegia. arrays (Table 3). Figures 16 and 17 show the LP band and the IP band low pass filtered at frequencies under $0.06 \mathrm{~Hz}$ to compare the overlapping frequency spans. The traces are similar and no information is lost by using the filterej IP trace, suggesting that the LP band is redundant information.

The attenuation around PSRF was studied by finding the frequency at which the Pwave signal went into the background noise on $\mathrm{HFZ}$ and plotting the results against distance and azimuth (Figs. 18, 19). There is an exponential decay of frequency with distance; only $m_{b}>6.0$ and $\Delta<330 \mathrm{~km}$ have energy at frequencies over $30 \mathrm{~Hz}$. Events located east of PSRF are more likely to have energy at frequencies over $20 \mathrm{~Hz}$, which is the result of the different tectonic regimes east and west of PSRF. Since energy over $30 \mathrm{~Hz}$ is not seen at PSRF, it may only be necessary to cover the $0.5-30 \mathrm{~Hz}$ frequency span with the IIF band.

State of health (SOH) information cnsures the quality of the data (pp 22-25). The information (Table 4) is valuable and useful in monitoring the system and keeping it running. Only SOH data on the communications needs to be improved. Also, a "semi" expert system that could monitor SOH in real time and warn the operator of problems would increase the usefulness and timeliness of the SOH information.

Funds were not available to evaluate DSVS in an operational mode similar to the evaluation of the National Seismic Stations in RSTN. We would expect however, that the performance of DSVS would be similar to that of RSTN since the same design principles were followed. 


\section{Acronyms and Abbreviations}

\begin{tabular}{|c|c|}
\hline AFTAC & Air Force Tactical Applications Center \\
\hline ARCESS & Arctic Experimental Seismic System \\
\hline $\mathrm{DAC}$ & Data Analysis Center \\
\hline $\mathrm{DCL}$ & data communications link \\
\hline DHL & downhole logic \\
\hline DOE & Department of Energy \\
\hline DSVS & Deployable Seismic Verification System \\
\hline EUS & eastern United States \\
\hline FIR & finite impulse response \\
\hline FSU & former Soviet Union \\
\hline GPS & Global Positioning Satellite \\
\hline $\mathrm{HF}$ & high frequency \\
\hline HPA & high power amplitude \\
\hline HRD & high resolution digitizer \\
\hline IP & intermediate period \\
\hline LP & long period \\
\hline MTBF & mean time between failures \\
\hline MTTR & mean time to repair \\
\hline NEIS & National Earthquake Information Service \\
\hline NORESS & Norwegian Experimental Seismic Syste:n \\
\hline NSS & National Seismic Stations \\
\hline NTS & Nevada Test Site \\
\hline PDE & Preliminary Determination of Epicenters \\
\hline PSRF & Pinedale Seismic Research Facility \\
\hline RAMS & Receiving and Monitoring Station \\
\hline RF & radio frequency \\
\hline RSS & Regional Seismic Station \\
\hline RSCP & Regional Station Cumberland Plateau \\
\hline RSNY & Regional Station New York \\
\hline RSON & Regional Station Ontario \\
\hline RSSD & Regional Station South Dakota \\
\hline RSTN & Regional Seismic Test Network \\
\hline RT & receiver/transmitter \\
\hline $\mathrm{SOH}$ & state of health \\
\hline TEG & thermoelectric generator \\
\hline UHL & uphole logic \\
\hline USGS & United States Geologic Survey \\
\hline WUS & western United States \\
\hline
\end{tabular}




\section{Introduction}

The Deployable Seismic Verification System (DSVS) was developed by the Department of Energy (DOE) through its national laboratories to support monitoring of underground nuclear testing treaties. According to the DSVS Development Plan (1987), the system was developed for the missions of declared test site monitoring associated with a Threshold Test Ban Treaty and general area monitoring associated with a Comprehensive Test Ban Treaty. The most likely deployment would be to the former Soviet Union (FSU). Because of the political climate at the time, DSVS requirements were very similar to those established in the late 1970's for the National Seismic Station (NSS). Those requirements included the following:

1. Provide reliable, high-quality seismographic data for regional and teleseismic analyses.

2. Provide reliable operation so that it would be impractical to induce or hide in failures.

3. Provide evidence of tampering with data and/or equipment.

4. Minimize intrusiveness to the host by minimizing deployment and maintenance activities.

5. Operate in a stand-alone mode with no external power supplied and no commands to the stations.

This report details the evaluation of a Remote Seismic Station (RSS) which was deployed at the Pinedale Seismic Research Facility of the Air Force Tactical Applications Center (AFTAC). Since no funds were available to operate the overall system in a "deployment operations mode" only general conclusions can be made regarding the operational capabilities (e.g. data availability, MTBF, MTTR). However, we were able to

choose from the available data to determine the station's seismic data acquisition in which we have high confidence.

\section{System Description}

The elements of the DSVS (Figure 1) are the Remote Seismic System (RSS), the Data Communications Link (DCL), the Receiving and Monitoring Stations (RAMS), and the Data Analysis Center (DAC). RSS is an unmanned seismic station for the acquisition of wide band, three-axis seismic data. There are two versions of RSS. With RSS-1, a three-axis, high-quality seismometer acquires the data and sends it to the downhole logic unit (DHL) where the data is conditioned, digitized and authenticated. State of health ( $\mathrm{SOH}$ ) information is also monitored by the DHL. The RSS-3 configuration has two boreholes, each with an associated seismometer and DHL. For both RSS versions, the uphole logic unit (UHL) merges the data from the DHL with surface state of health data, formats and time tags the data and sends it to the DCL. The primary power source for the RSS is provided by the burning of propane gas and using thermoelectric generators (TEGS) to translate the heat to electrical energy.

The DCL transmits the data from the RSS to RAMS by use of a communications satellite. The remote terminal is a low power RF communications system that transmits the data from the field site to the communications terminal at RAMS. The terminal at 


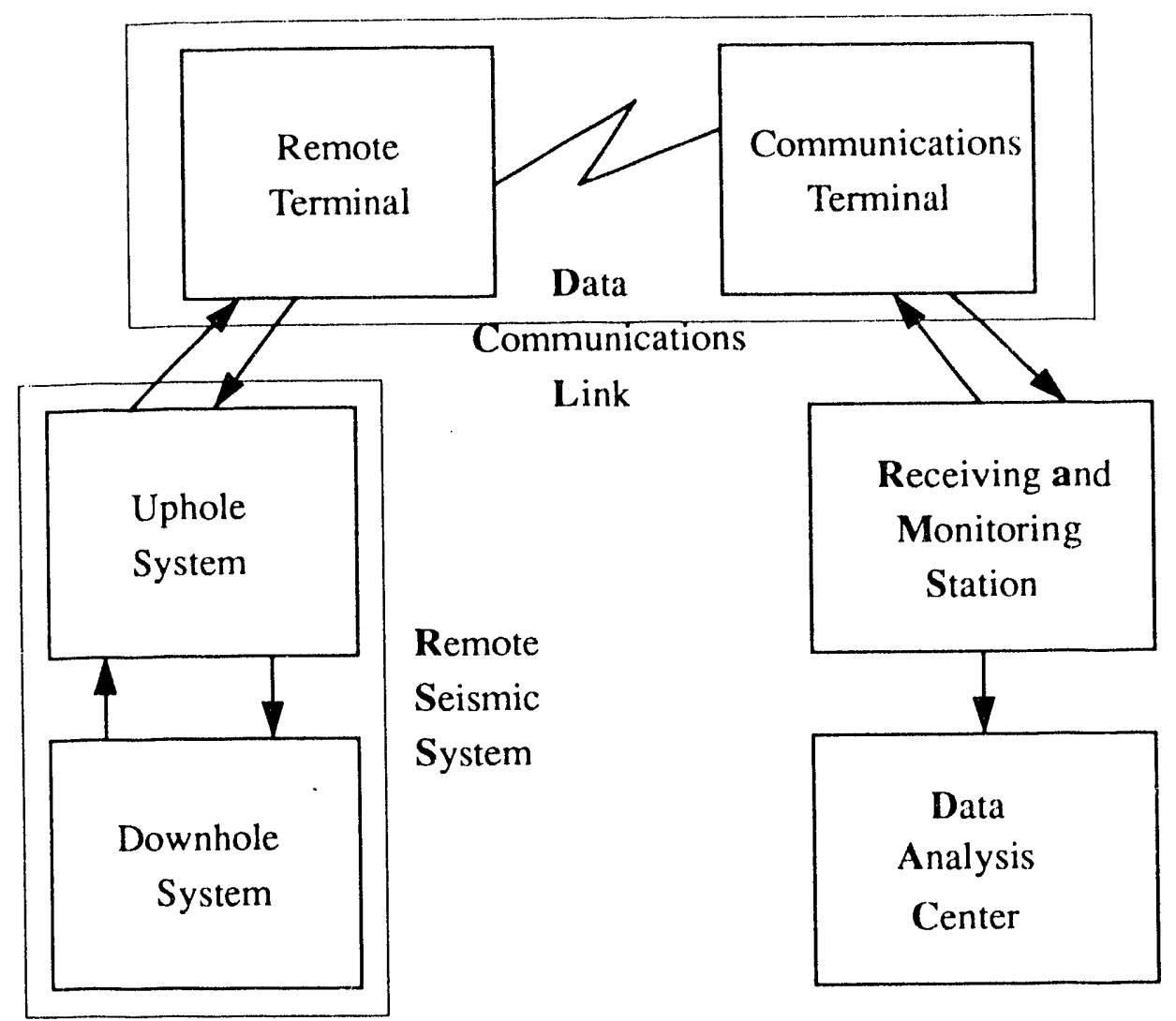

Figure 1. The different components of DSVS include the Remote Seismic Station (RSS) which consists of an uphole system and a downhole system. The data is transmitted from the RSS to the Receiving and Monitoring Station (RAMS) by the Data Communications Link (DCL). Data Analysis Centers (DAC) receive data from RAMS.

RAMS receives the satellite signal and demodulates it so that the data can be used. The function of RAMS is to verify the authenticity of the data received, to assess the operational status of the RSS and to pass the seismic data to analysis centers (DAC). One DAC was developed at Lawrence Livermore National Laboratory, but it is not desuribed or evaluated in this report.

One DSVS station, of the RSS-3 configuration, has been deployed at the Pinedale Seismic Research Facility (PSRF) near Boulder, Wyoming since May 1990. The seismometers are deployed with the holelocks at depths of 42 feet. A Teledyne Geotech S3 seismometer provides 3-axis HF coverage from 0.5 to $50 \mathrm{~Hz}$. The sampling rate is $200 \mathrm{sps}$ with a 24-bit digitizer. A Teledyne Geotech 54000 provides 3 -axis coverage in both the IP $(0.01-2.5 \mathrm{~Hz})$ and $\mathrm{LP}(0.02-0.05 \mathrm{~Hz})$ bands. The sampling rate in the IP band is 10 sps with a 24-bit digitizer. In the LP band the data is sampled at 1 sps and a 16-bit digitizer is used. 


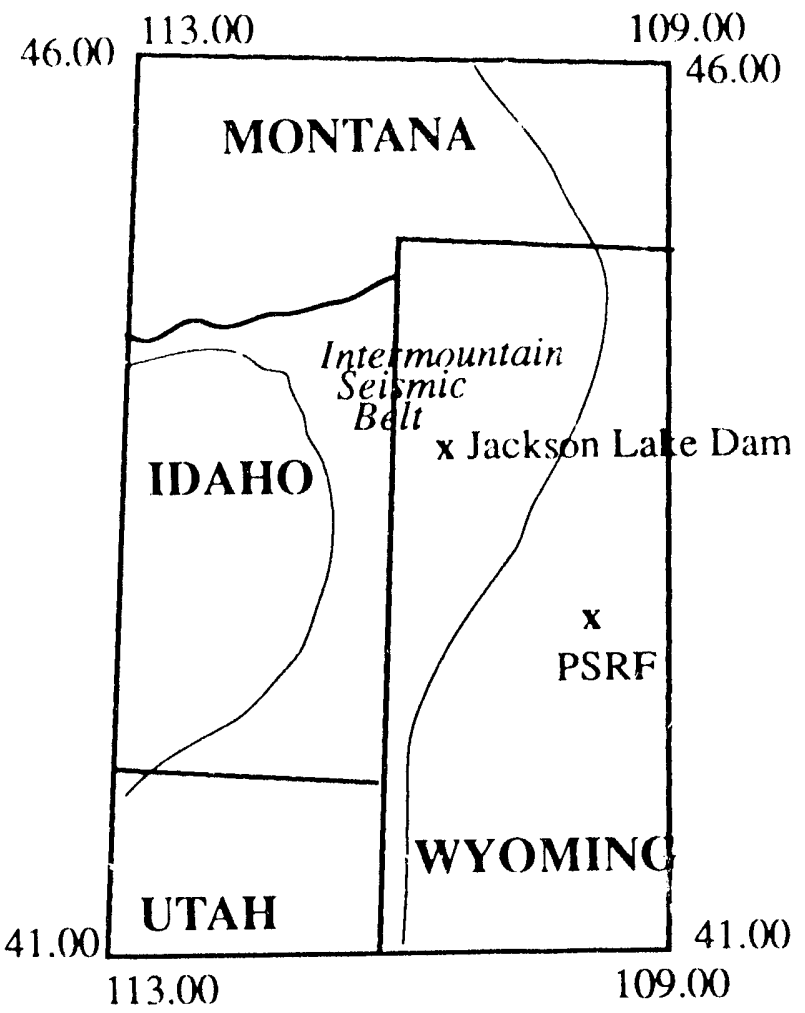

Figure 2. A map showing the location of PSRF in western Wyoming at coordinates $42.77^{\circ} \mathrm{N}$ and $1\left(19.55^{\circ} \mathrm{W}\right.$

\section{Site Description}

PSRF is located in western Wyoming on the western front of the Wind River Mountains in the northern end of the Green River Basin (Figure 2) at $42.77^{\circ} \mathrm{N}$ latitude and $109.55^{\circ} \mathrm{W}$ longitude. The site for DSVS is situated on the west side of a bluff that strikes approximately $30^{\circ}$ west of north. The boreholes were drilled into a saddle with the antenna and equipment shelter ENE of the boreholes. The rocks in the area are granodiorites to porphyritic granite from the 2600 Ma age group. Seismically, the site is approximately $100 \mathrm{~km}$ east of the Intermountain Seismic Belt, a band of seismic activity that runs from south central Utah into Montana.

\section{System Noise}

There are various sources of background noise at a seismic station (Taylor, 1981), such as cultural noise (traffic, power supplies, oil industry equipment) and meteorological phenomena (mainly wind). Another source of noise is the self noise of the system itself, i.e. the noise coming from the seismometer, the analog filters and the high resolution digitizers (HRD). This self noise will manifest itself as an additional background noise component.

To evaluate the system noise we collected background noise data on random days from March 1991 through August 1992 at times after 5pm local time. Times were chosen 
close to local midnight to reduce the cultural noise effects. Two hundred and fifty seconds of HF data, 500 seconds of IP data and 5000$)$ seconds of LP data viere collected on all three axes for analysis of each band. Spectra were calculated on all the data using 512 point Hanning windows with 0.5 overlap over the entire data window. A median spectrum was calculated for the axes in each band and compared to a conservative estimate of the seif noise of the system. The medians were also compared to the USGS-Peterson low noise model, a composite from different world-wide stations of the lowest measurements of noise in a particular frequency band. All spectral analysis was done in velocity.

One hundred and forty four spectra in the HF band were used to calculate the HF medians shown in Figure 3. The general shape of the spectra follow the USGS-Peterson low noise model. with steep fall-off of $75 \mathrm{~dB}$ per decade between 0.5 and $1 .() \mathrm{Hz}$. From $1 .()$ to $4.0 \mathrm{~Hz}$ the spectra flatten and then fall-off again (30 dB per decade) from 4.0 to $50.0 \mathrm{~Hz}$. The steep roll off between 50 and $70 \mathrm{~Hz}$ is due to the FIR filter in the HRD. The median spectra are below the USGS-Peterson low noise model at all frequencies except a band between 3 and $6 \mathrm{~Hz}$. The horizontal axes have higher noise in this band than the vertical axis. Because the background noise level and USCiS-Peterson low noise model fit well together we can be confident that the transfer function for the seismometer is correct. We also found that PSRF is a quiet site at frequencies over $6 \mathrm{~Hz}$. The modeled self noise of the system is below the median spectra until approximately $15 \mathrm{~Hz}$ and crosses the USGS-

Peterson low noise model at around $32 \mathrm{~Hz}$. We used a conservative estimate of the analog filter noise in the self noise model, and feel that the data are good at frequencies up to 40

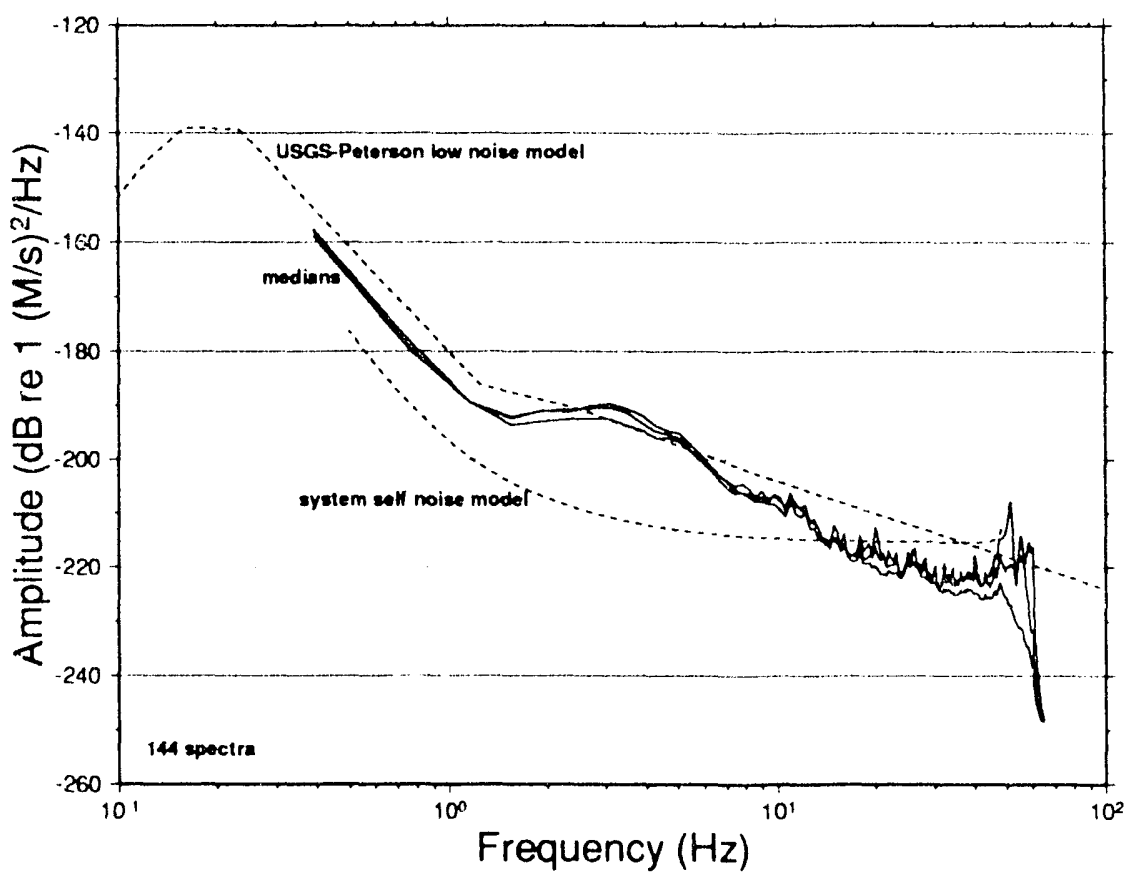

Figure 3. Median velocity noise spectra for the vertical, north and east components of the HF band, calculated from 144 spectra. 
$\mathrm{Hz}$. If the background noise is independent there should be no coherency between the three axes. We only found coherency in the HF band at four specific frequencies: 25,38 , 48 and $55 \mathrm{~Hz}$.

One hundred and forty thi ee spectra in the IP band were used to calculate the medians shown in Figure 4. The general shape of the spectra roughly follow the USGSPeterson low noise model. The spectra increase at $55 \mathrm{~dB}$ per decade from 0.02 to $0.15 \mathrm{~Hz}$. They peak at $0.15 \mathrm{~Hz}$, then roll off at $70 \mathrm{~dB}$ per decade to $1.0 \mathrm{~Hz}$. The spectra flatten from $1.0 \mathrm{~Hz}$ to $2.5 \mathrm{~Hz}$, where the data roll off due to the HRD FIR filter. The horizontal axes do not have as good performance as the vertical axis at frequencies less than $0.04 \mathrm{~Hz}$, because of a higher noise floor at $0.01 \mathrm{~Hz}$ on the horizontal modules. The median IP spectra are below the USGS-Peterson low noise model at frequencies over $0.15 \mathrm{~Hz}$. At frequencies less than that, the median and USGS-Peterson low noise model have similar amplitudes, indicating the transfer function for the seismometer is good. The modeled system self noise is below all the spectra over the entire frequency band except for the vertical axis at the low end of the band (0.01-0.02 Hz). Since we used a conservative self noise model, the data at these frequencies should be good. The two sinall peaks at 1.0 and $2.0 \mathrm{~Hz}$ on the Eaxis are due to the coupling through the borehole cables of the system electronics.

One hundred and twenty four spectra in the LP band were used to calculate the medians shown in Figure 5. The general shape of the spectra from 0.02 to $0.05 \mathrm{~Hz}$ roughly follow the USGS-Peterson low noise model. On the vertical axis the spectrum is flat from

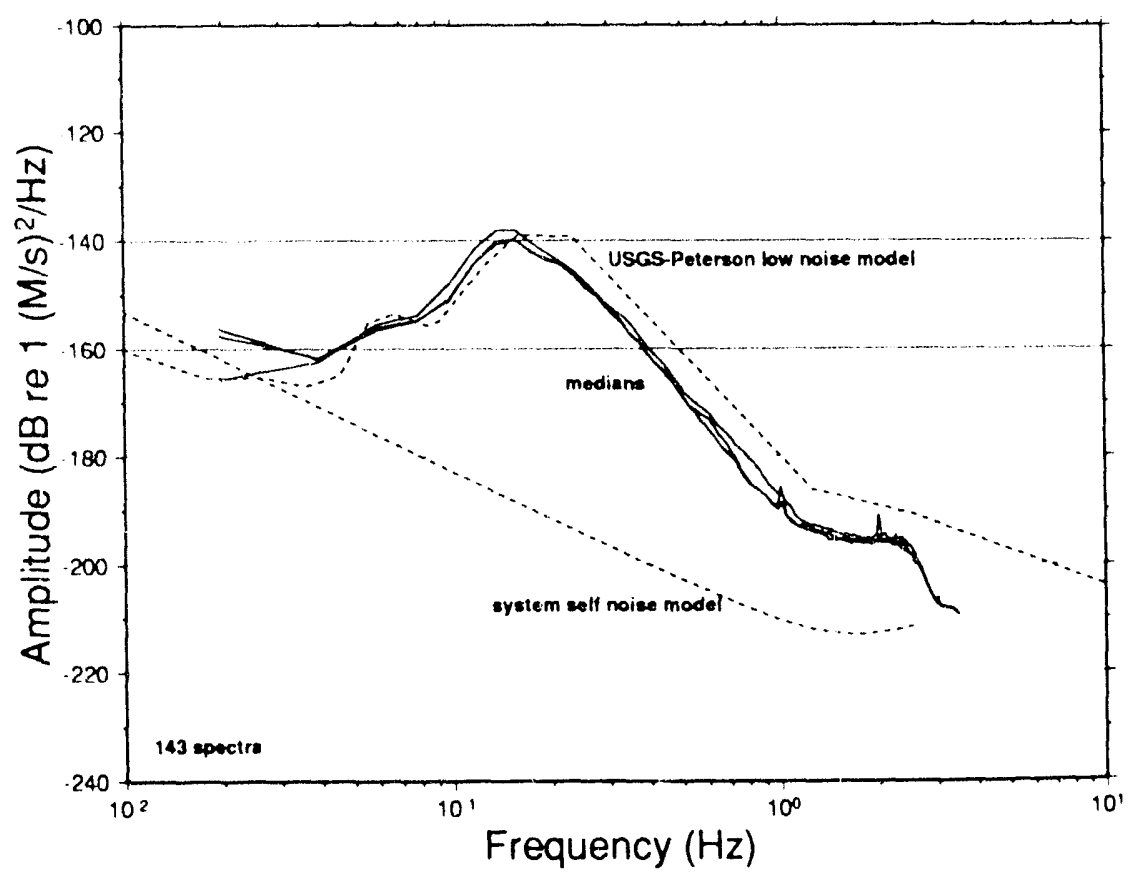

Figure 4. Median velocity noise spectra for the vertical, worth and east components of the IP hand, calculated from 143 sfectra. The small peaks at 1.0 and $2.0 \mathrm{~Hz}$ on the E-comporient are due to modulation of the system electronics. 


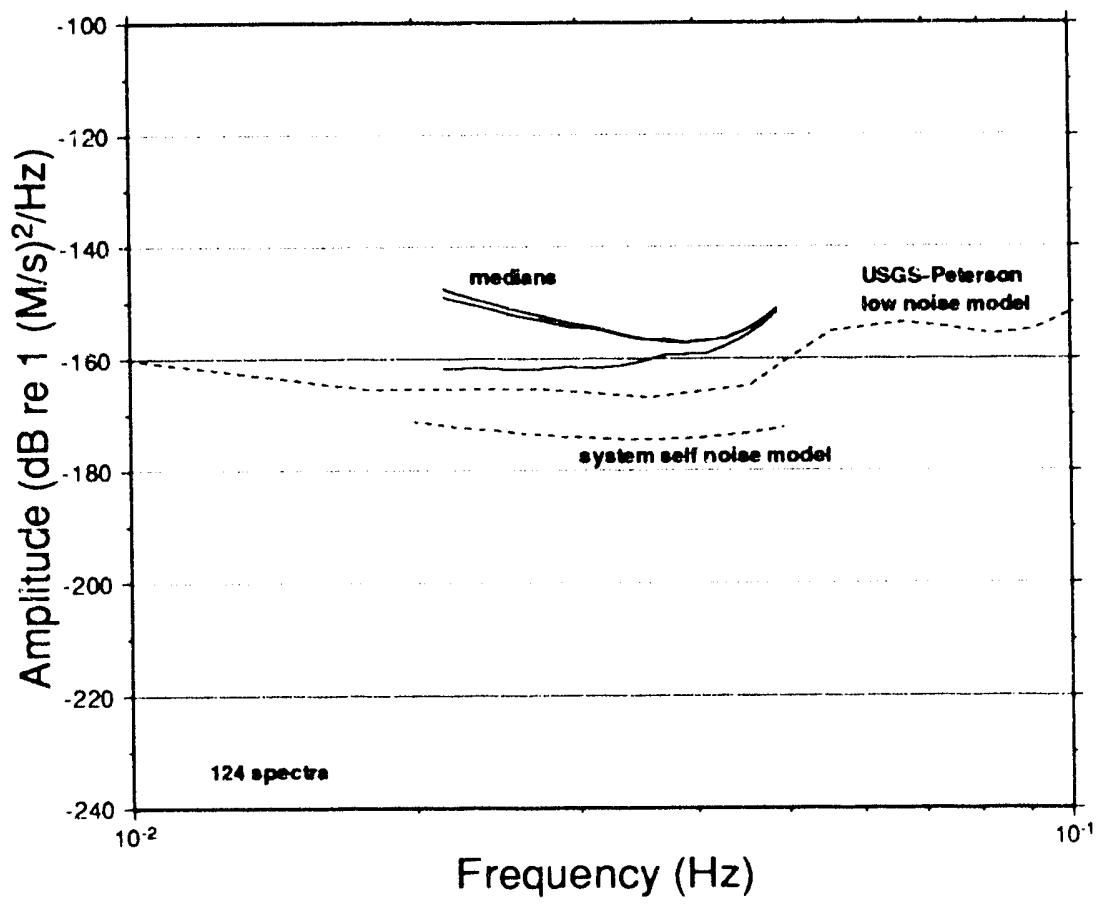

Figure 5. Median velocity noise spectra for the vertical, north and east components of the LP band, calculated from 124 spectra.

0.02 to $0.04 \mathrm{~Hz}$, but on the horizontal axes the spectra decrease at a rate of $45 \mathrm{~dB}$ per decade. This is because the horizontal modules have a higher noise floor at frequencies around $0.01 \mathrm{~Hz}$ than the vertical module. On all three axes the spectra increase at approximately $120 \mathrm{~dB}$ per decade between 0.04 and $0.05 \mathrm{~Hz}$. The median spectra are above the USGS-Peterson low noise model at all frequencies in the LP band. The modeled self noise of the system is below all the spectra and has a similar shape. Part of the discrepancy in this band is due to the performance of the 16 bit digitizer, which actually performs as a 14 bit digitizer.

DSVS was designed with overlapping frequency bands. The HF and IP bands overlap in the frequency range of 0.5 to $2.5 \mathrm{~Hz}$. In this frequency span the medians in the $\mathrm{HF}$ band and IP band are very close in amplitude (Figures 3 and 4). The IP band is slightly lower ( 3 to $7 \mathrm{~dB}$ ) than the HF band, but the shape of the medians is the same. In both bands the medians are below the low noise model. The two seismometers recording data from 0.5 to $2.5 \mathrm{~Hz}$ are both doing an adequate job. The IP and LP bands overlap in the frequency range of 0.02 to $0.05 \mathrm{~Hz}$ (Figures 4 and 5). In this frequency span the medians in the LP band are 3 to $8 \mathrm{~dB}$ above the median in the IP band and all are above the low noise model. The shape of the medians are similar, except there is more of an increase in slope from 0.035 to $0.05 \mathrm{~Hz}$ in the LP band.

The IP and LP bands are recorded with the same seismometer, a 54000. The differences seen in the spectra are due to analog filters and digitizers used to collect the data. 
The comparison of the two bands points out that the IP band covers the entire LP band and does a slightly better job of recording the data. This suggests that a single band, using modern low noise 24 bit high resolution digitizers would be adequate for covering the frequency span of 0.01 to $2.5 \mathrm{~Hz}$.

\section{Meteorological Phenomena}

Wind velocity is a major meteorological phenomenon that can cause an increase in background noise levels. Winter storms and spring run-off have also been cited as reasons for increased noise levels (Basham and Whitman, 1966; Smart and Sproules, 1980; Fyen, 1987). The changes to the background noise due to meteorological phenomena can be site specific, but are important to study to determine their effect on system performance. We also are interested in determining the advantage of having anemometers installed with DSVS at PSRF.

To look at the effect of wind, the noise data were separated into four groups based on the average wind speed from the anemometer at the time the data was collected.

Median spectra were calculated for wind speeds less than $0.1 \mathrm{mph}$, between 2.0 and 5.0 mph., between 8.0 and $15.0 \mathrm{mph}$ and greater that $15.0 \mathrm{mph}$. Seasonal variation was studied by separating the data into different seasons (Table 1), and comparing the median spectra calculated in each frequency band.

Using the anemometer located north of the antenna, we found that as wind speed varied from 0 to $30 \mathrm{mph}$, only the HF band had any noticeable changes in the background noise. In Figure 6, median spectra in the HF band have been calculated using spectra from times with different wind speeds. As the wind speed increases, the level of the entire spectrum increases and peaks around 10,26, 38 and $48 \mathrm{~Hz}$ are larger. We believe that these peaks are due to the wind blowing on the antenna located 15 meters ENE of the borehole or through the fence surrounding the area, causing them to resonate. Backazimuths calculated from these peaks indicate that the source of all peaks is from $30^{\circ}$ to $60^{\circ}$ east of north, which corresponds well to the antenna. The broad peak from 9 to $12 \mathrm{~Hz}$, is also seen when the wind is very low, so we suspect oil jacks in the area may be the source of this noise peak. There can be differences of over $10 \mathrm{~dB}$ between noise levels with wind speeds less than 1.0 m.p.h. and noise levels at the windiest periods. It is only because we have anemometers installed at the station that we can correlate wind at PSRF with the background noise.

Figures 7, 8 and 9 show the seasonal variation seen in the noise levels at DSVS at PSRF. The median noise in the winter is 2 to $14 \mathrm{~dB}$ higher than the median noise in summer at frequencies less than $0.9 \mathrm{~Hz}$ (IP, LP bands). The spring and autumn median noise levels are very close, and fall in-between winter and summer. At frequencies over $1 \mathrm{~Hz}$

Table 1-Breakdown of scasons uscd for scasonal variation

$\begin{array}{ll}\text { Spring: } & \text { March, April and May } \\ \text { Summer: } & \text { June, July and August } \\ \text { Autumn: } & \text { September, October, November } \\ \text { Winter: } & \text { December, January, February }\end{array}$




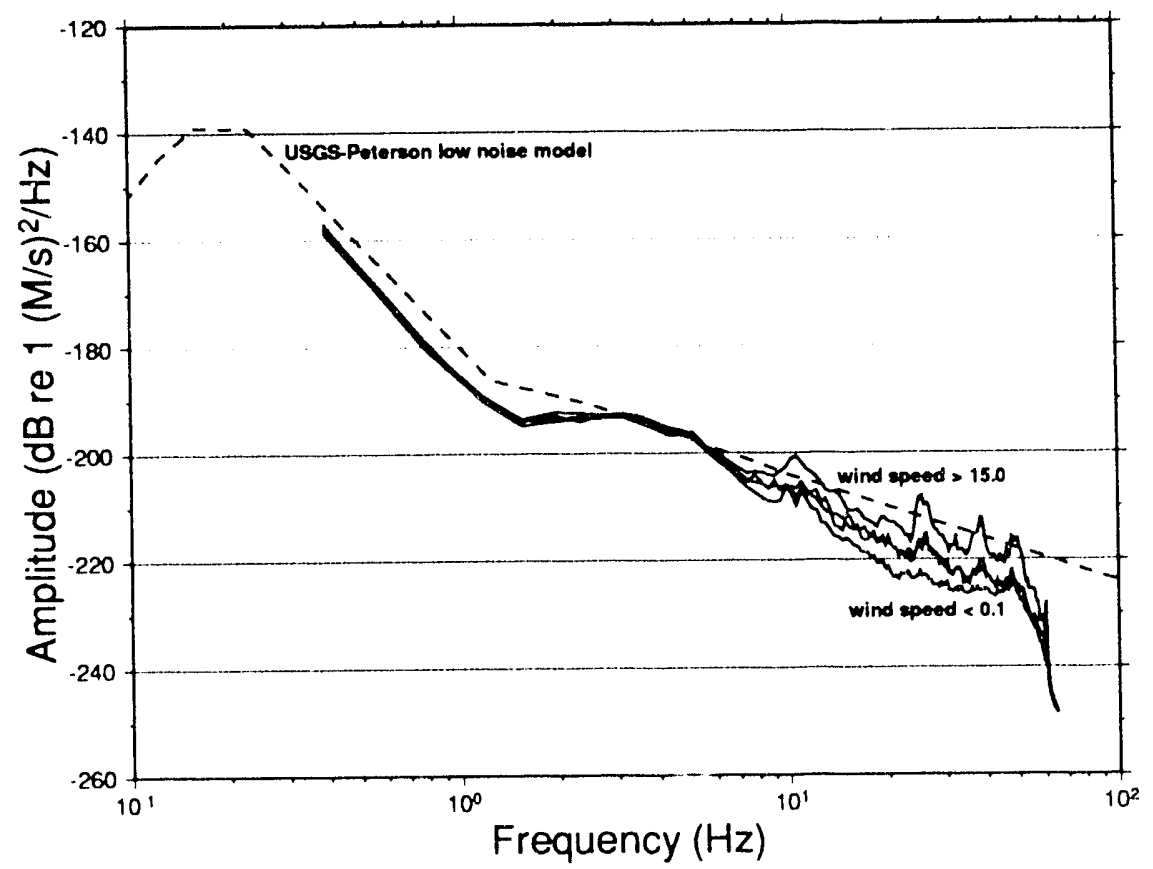

Figure 6. Median velocity noise spectra for different values of average wind speed on the HF band.

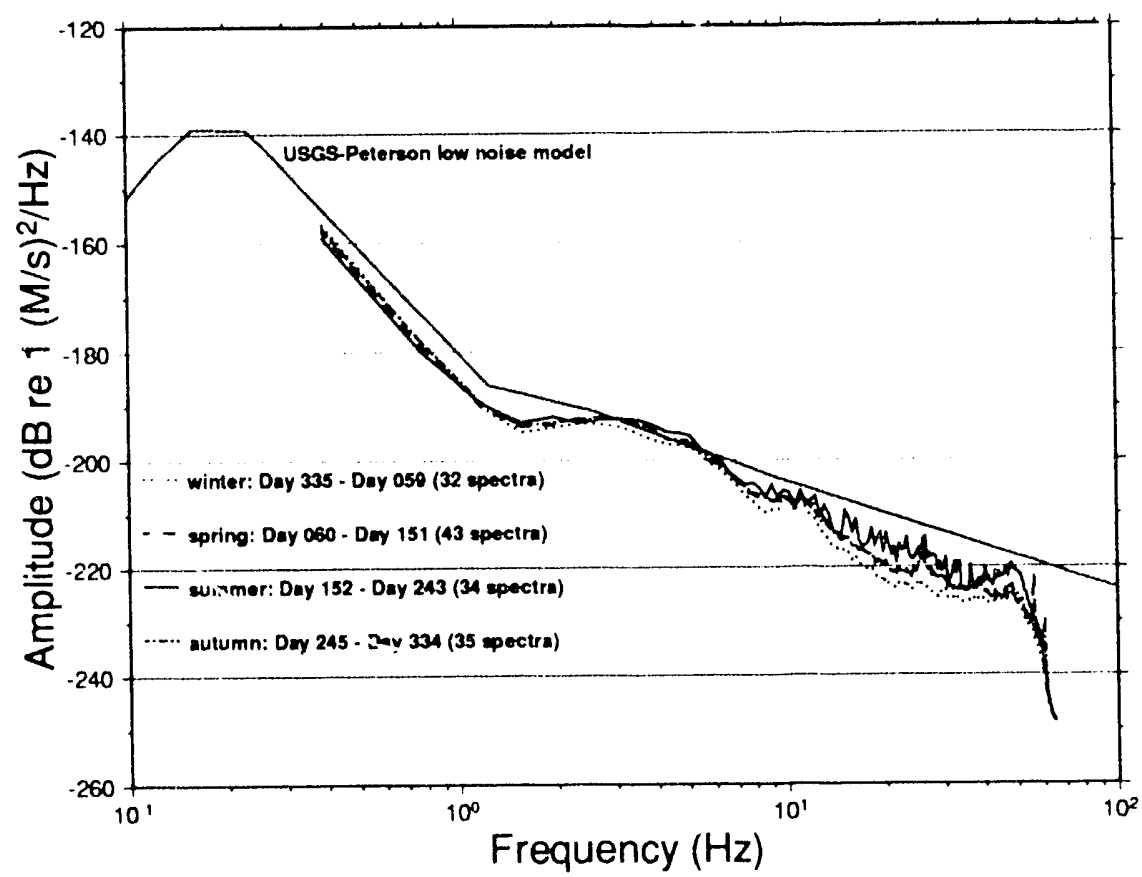

Figure 7. Median velocity noise spectra for different seasons on the HF band. Over frequencies of approximately $2 \mathrm{~Hz}$, the summer noise level is the highest and the winter noise level is the lowest. 


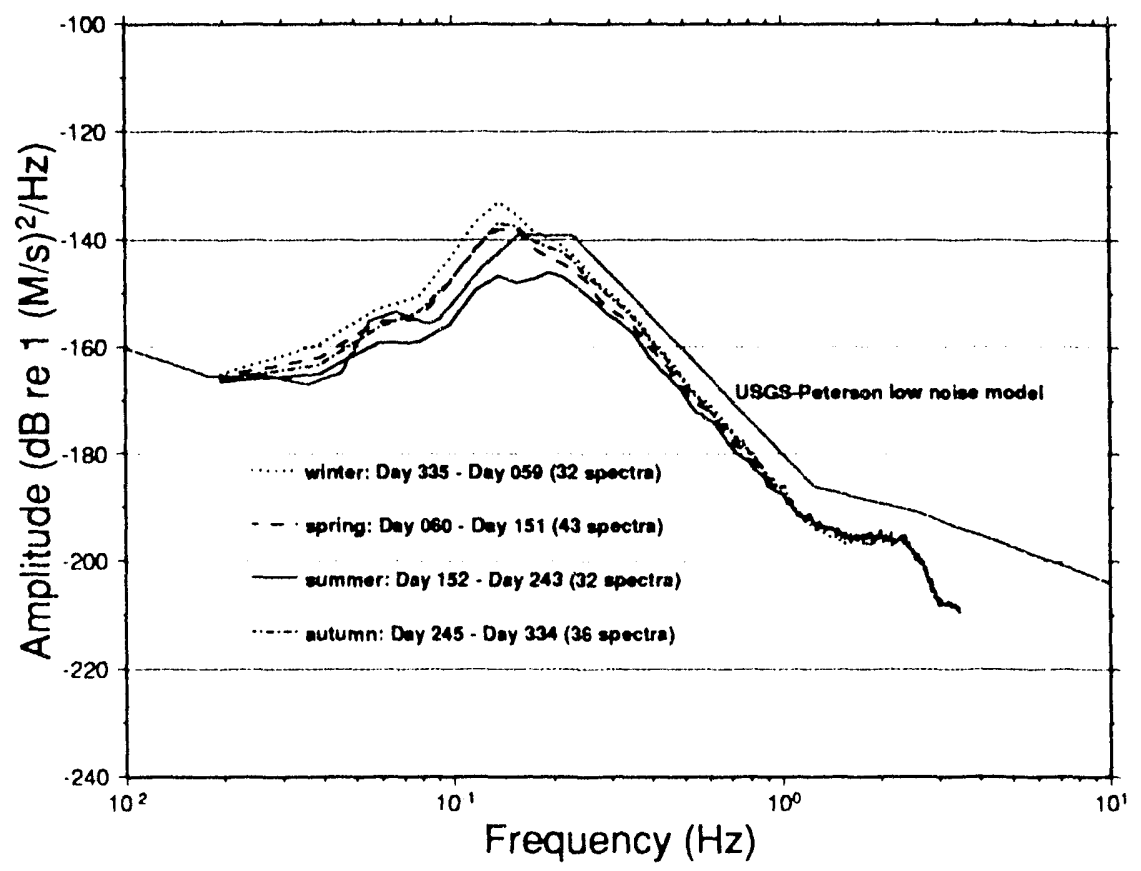

Figure 8. Median velocity noise spectra for different seasons on the IP band. The winter noise level is the highest and summer noise level is the lowest over most of the frequency range in this band.

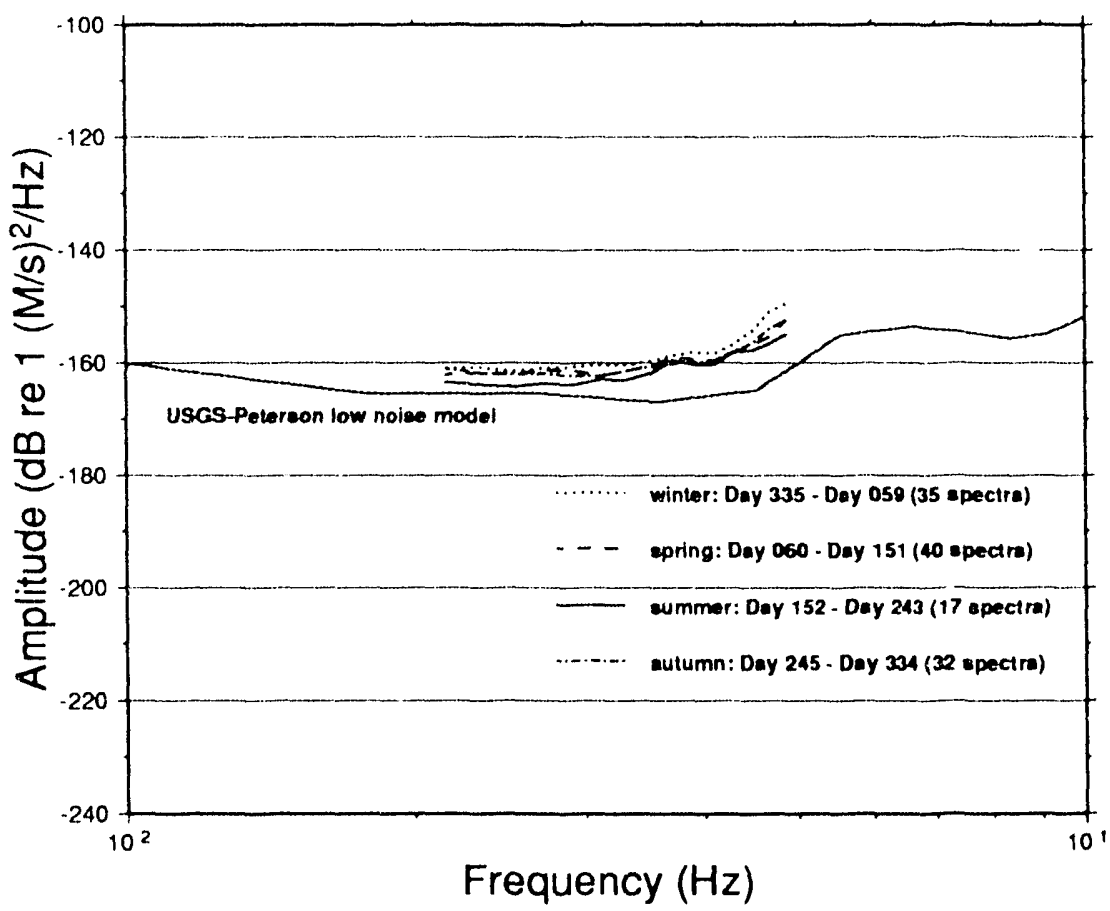

Figure 9. Median velocity noise spectra for different seasons on the LP band. The winter noise level is the highest, summer noise level the lowest over this frequency band. 
(HF band), the lowest median noise is in the winter; the highest median noise is in the summer; and the median noise in spring and autumn are almost identical and fit inbetween. Meteorological disturbances during the winter have been considered to be the major factor as to why winter noise levels are high at the longer periods (Basham and Whitman, 1966; Smart and Sproules, 1980). In Norway, Bungum et al. (1971) and Ringdal and Bungum (1977) found that noise levels were highest in the fall and lowest in summer for frequencies under $2 \mathrm{~Hz}$. Fyen (1987) extended the frequency band to $20 \mathrm{~Hz}$ and studied the noise at specific frequencies for a period of a little longer than a year. He found the highest noise levels at frequencies over $2 \mathrm{~Hz}$ were in the spring and contributed this increase to the snow melting and increasing the water flow in nearby rivers. At PSRF, we looked at the average wind speed in the different seasons to see if an increase in wind during the summer could explain the higher noise level at the higher frequencies. In our data set, the average wind speed in the winter is very low; it is less than $1.0 \mathrm{mph}$ for $88 \%$ of the events. It is only in the summer when the average wind speed is over $15 \mathrm{mph}$. In Figure 6 we see a difference of 5 to $10 \mathrm{~dB}$ between the median spectra for wind speeds over $15 \mathrm{mph}$ and wind speeds less than $1.0 \mathrm{mph}$. The higher noise levels in the summer can be accounted for by the increase in velocity of the wind.

\section{Seismic Response}

It is important to determine how well DSVS at PSRF records seismic events. Some of the response of the instrument is site specific, but we need to determine if there are any limitations in the instrumentation. To evaluate the seismic response we studied the response of the system to known event data. This includes looking for specific arrivals, determining amplitude response and finding the backazimuth estimation capabilities of the system. We also wanted to determine the type and amount of data processing needed to look at the events, compare the overlapping frequency bands and evaluate the importance of both recording the data to $60 \mathrm{~Hz}$ and the LP band.

A database of 91 events occurring within $20^{\circ}$ of PSRF was collected to evaluate the response of the system. The events have known locations from the Preliminary Determination of Epicenters (PDE) bulletin of the National Earth quake Information Service (NEIS). A map of the events is in Figure 10. The magnitudes 0 . the events include local magnitudes $(\mathrm{ml})$ from various networks in the western U.S. that range from 2.0 to 4.9 , and body-wave magnitudes $\left(m_{b}\right)$ calculated by NEIS. The $m_{b}$ magnitudes range from 2.5 to 6.4. Since we had known locations for the events we started by looking for the different phases $\left(\mathrm{P}_{\mathrm{n}}, \mathrm{P}_{\mathrm{g}}, \mathrm{S}_{\mathrm{n}}\right.$ and $\left.\mathrm{L}_{\mathrm{g}}\right)$ to see if they arrived at the times they were supposed to according to the Jeffrey-Bullen tables. The highest zero-to-peak amplitude in the first 10 seconds was found and used to calculate a magnitude with Evernden's western United States (WUS) magnitude formula (Evernden, 1967). Any processing of the data, i.e. filtering, was documented and the frequency at which the signal went into the background noise on the vertical axis of the HF band was found to get an idea of the attenuation around PSRF. The response of the overlapping frequency bands was compared both spectrally and by comparing the traces. And finally, a backazimuth was calculated following the method of Walck and Chael (1991). 


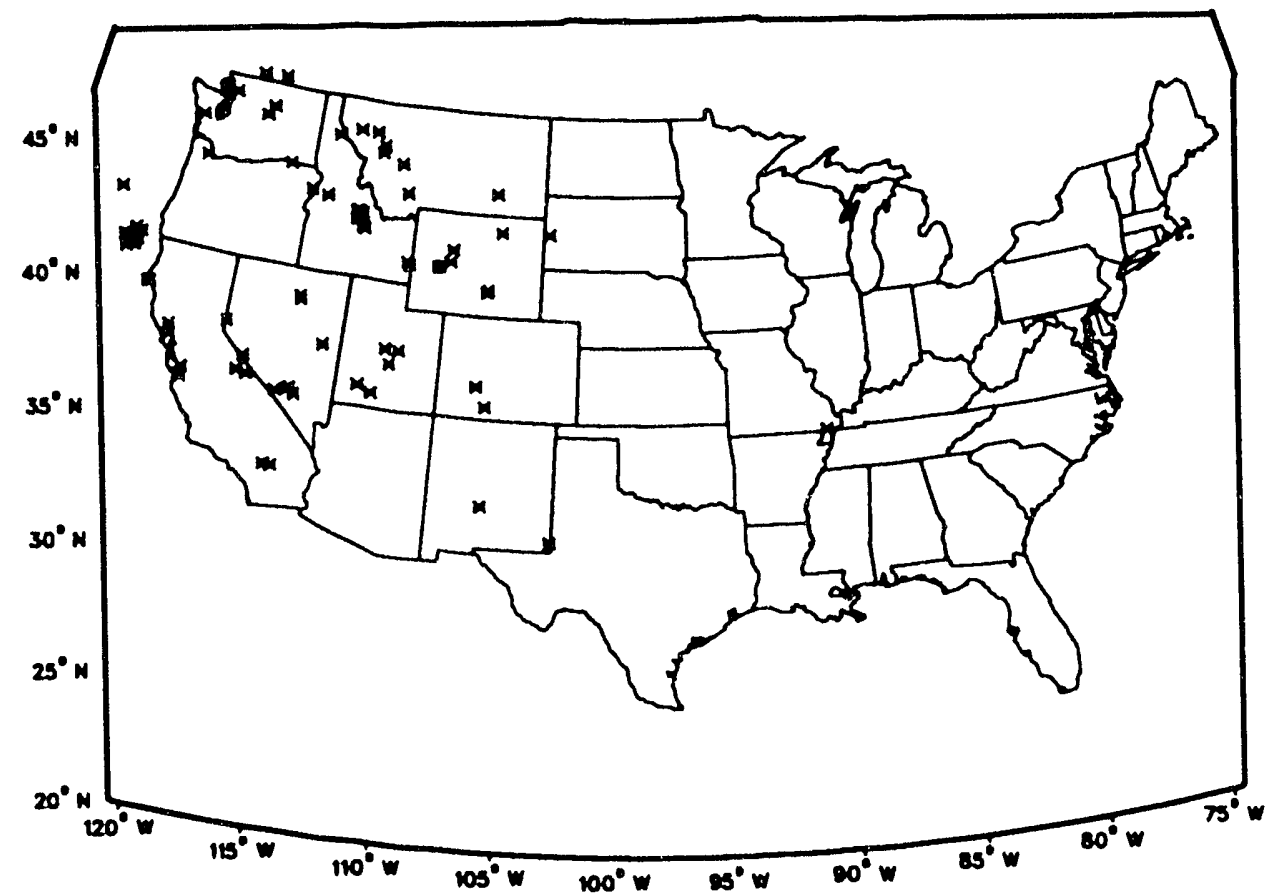

Figure 10. Map of events uscd to study the seismic response of DSVS. All the events (x) are within $20^{\circ}$ of PSRF (box).

P-arrivals were seen for 75 of the 91 events in the database. Most of the sixteen events that were not recorded on DSVS at PSRF were over $900 \mathrm{~km}$ away and had small local magnitudes (3.0-3.5). Figures 11 and 12 have examples of events recorded at DSVS. The first event (Fig. 11) is a local magnitude 3.0 earthquake occurring $236 \mathrm{~km}$ easi of PSRF. Good $P_{n}$ and $L_{g}$ arrivals are seen on both the HF and IP bands, but there is nothing on the LP band. Figure 12 shows an earthquake off the northern coast of Californid that has an $m_{b}=6.0$. The $L_{g}$ arrival is seen clearly on the LP band for this event, which is 1262 $\mathrm{hm}$ away. No $\mathrm{P}_{\mathrm{g}}$ arrivals were seen for events at distances over $1150 \mathrm{~km}$, which fullows the typical $\mathrm{P}_{\mathrm{g}}$-distance relationship. For 51 events in the database there was no $\mathrm{S}_{\mathrm{n}}$ arrival. Other authors have noted the absence of observations of $S_{n}$ in the WUS, (Molnar and Oliver, 1969; Der et. al., 1982) and attribute it to upper mantle attenuation or discontinuity of the waveguide. At PSRF, the $S_{n}$-wave was mostly seen for events at short distances $(<250 \mathrm{~km})$ and for high $\mathrm{m}_{\mathrm{b}}$ events more than $1200 \mathrm{~km}$ away. The $\mathrm{L}_{\mathrm{g}}$-wave was seen for almost all the events in the database. Events with no $\mathrm{L}_{\mathrm{g}}$-wave were those at distances less than $120 \mathrm{~km}$ from PSRF and some events off the Oregon and northern California coasts.

\section{Data Processing}

We documented the data processing needed to detect events with DSVS at PSRF to determine how easily events were detected and what aspects of the system hinder detec 

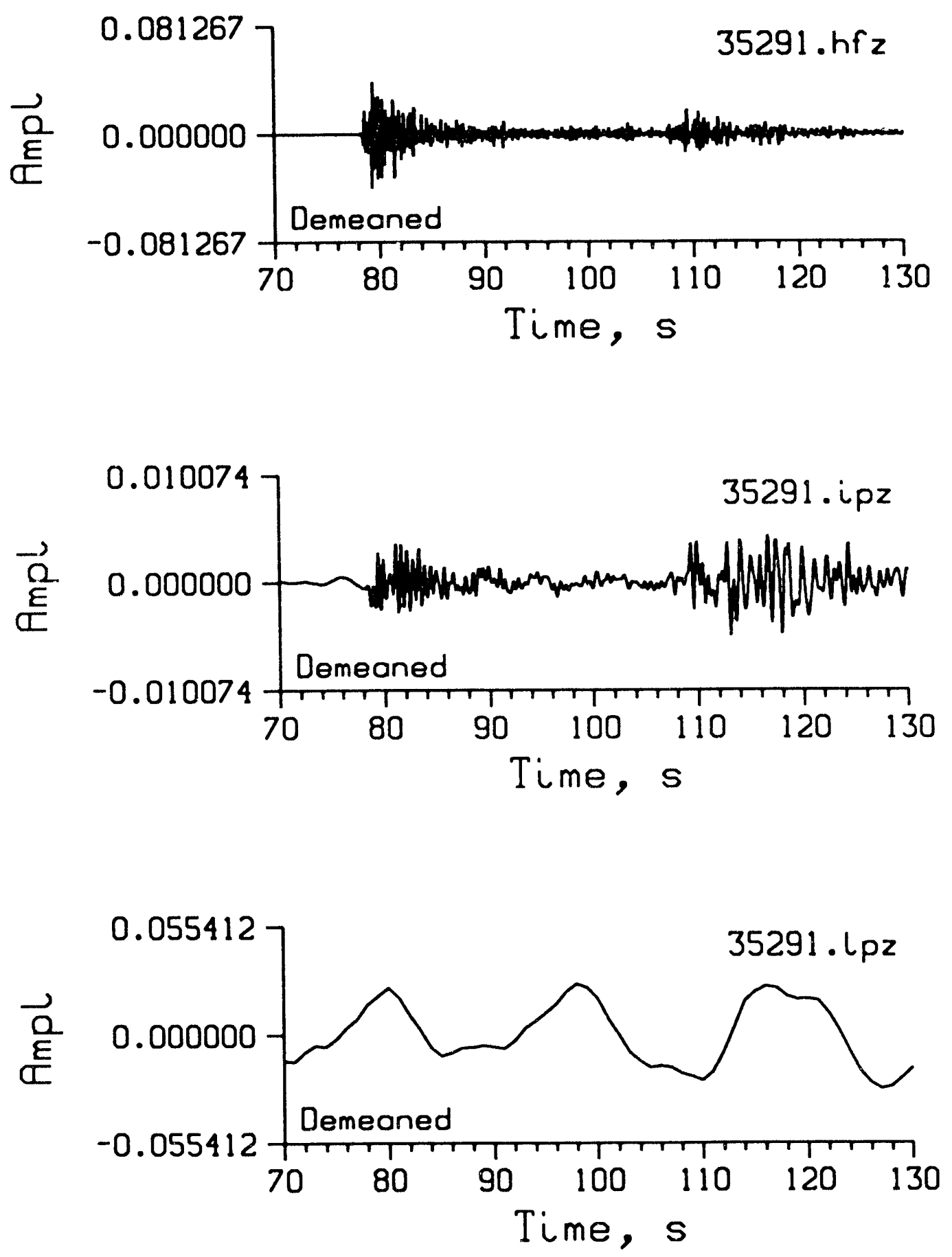

Figure 11. A local magnitude 3.0 carthquake occurring $236 \mathrm{~km}$ east of PSRF on December 18, 1991. Good $P_{n}$ and $L_{g}$ arrivals are seen on the HF and IP bands, but there is nothing on the LP band. 

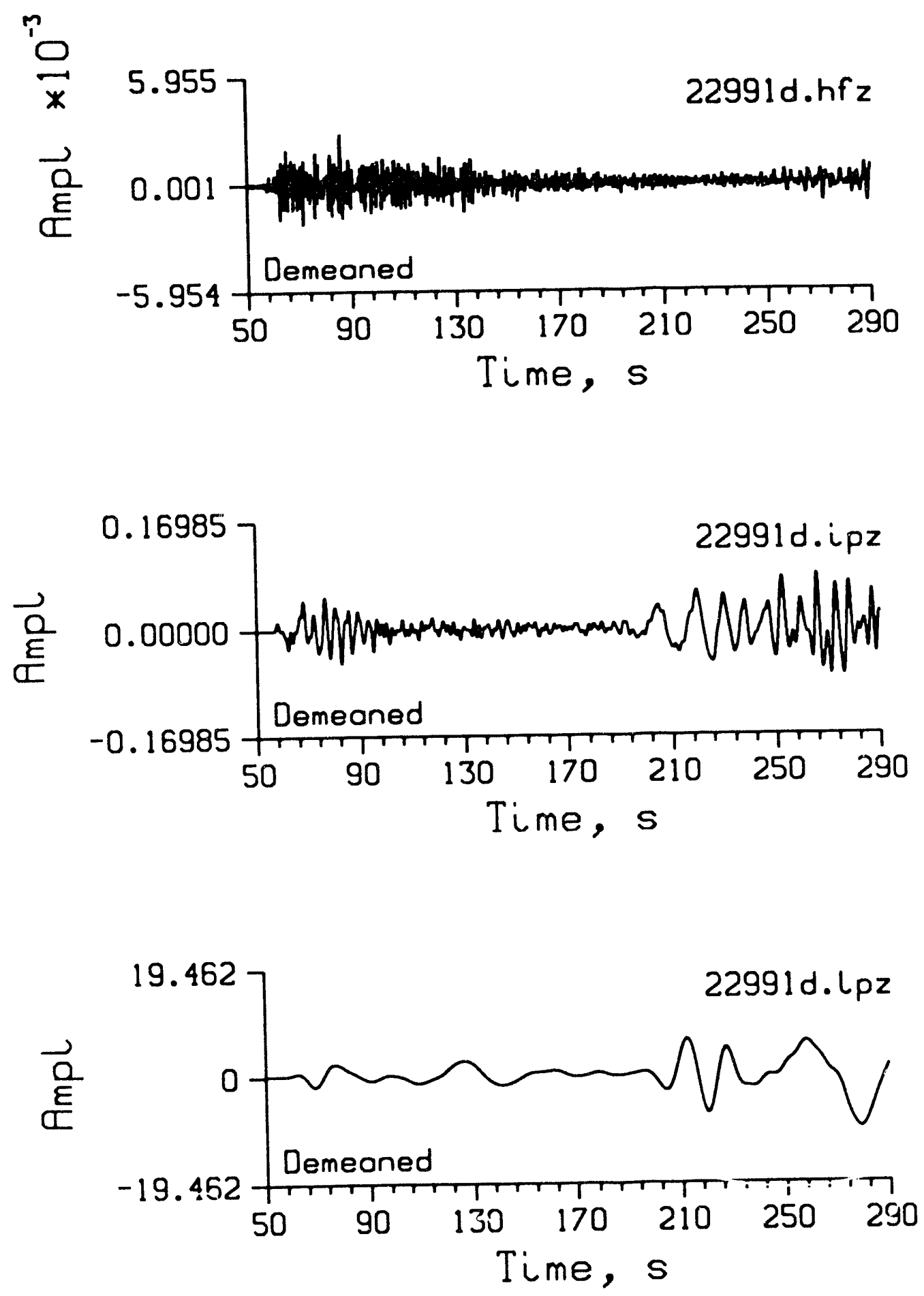

Figure 12. A m $\mathrm{m}_{\mathrm{b}}=6.0$ earthquake occurring off the coast of California, $1262 \mathrm{~km}$ from PSRF on August 17 , 1991. Good $P_{n}$ arrivals are seen on all bands, and good $L_{g}$ is seen on IP and LP. 
tions. Thirty-six events were seen :yithout filtering on the HF band. These included all the events occurring within $350 \mathrm{~km}$ of PSRF, all events with $m_{b}$ over 4.6 and all events located east of PSRF (azimuths $<163^{\circ}$ ). The remaining 39 events were only seen on the $\mathrm{HF}$ band when the data was low pass filtered at frequencies less than $4 \mathrm{~Hz}$. Figure 13 shows a $m_{b}=4.3$ earthquake located over $1200 \mathrm{~km}$ west of DSVS that was not detected on the HF band until the data was filtered. There is no indication of a seismic event on the demeaned trace of the data. Filtering is also needed on the IP band to get rid of the low frequency noise. For a large number of the 39 events, high pass filtering on the IP band was needed to get good arrival times. The LP band in Figure 13 shows a good $\mathrm{L}_{\mathrm{g}}$ arrival. For this particular event, the LP band has the best detection. What we found was that preprocessing of the data was needed for slightly over one half of the events detected on DSVS. A lot of the preprocessing was necessary because we are using wide bandwidths to record the data. For small magnitude events and events at large distances, the local high frequency noise obscures the signal.

\section{Amplitude-Magnitude Relationship}

The relationship of the zero-peak amplitude of an event and the magnitude depends upon the distance from the event to the recording station and the tectonic regime. In general, at PSRF the largest zero-peak amplitudes measured in volts during the first 10 second of the $P$-arrival are seen for events less than $300 \mathrm{~km}$ away and for events more than $8(0) \mathrm{km}$ away with NEIS $\mathrm{m}_{\mathrm{b}}$ magnitudes over 5.0. For the large NEIS $\mathrm{m}_{\mathrm{b}}$ events occurring over $8(0) \mathrm{km}$ west of PSRF, magnitudes were calculated using Evernden's WUS magnitude formula:

$$
m_{b}(\text { WUS })=-7.55+1.2[\log (A / T)+3.04(\log (\Delta)]
$$

where $\mathrm{A}$ is the zero-peak amplitude in nanometers, $\mathrm{T}$ is the period in seconds and $\Delta$ is the distance in kilometers. When compared to the NEIS $m_{b}$ magnitudes, the result is a leastsquares fit to a line with a slope of 1.1 (Figure 14). The magnitudes measured by DSVS using the WUS formula are a good match to the NEIS magnitudes, so the transfer function used to convert the data to displacement is correct.

\section{Backazimuth Estimation}

To determine the accuracy of backazimuths of events calculated from DSVS at PSRF, we followed the method of Walck and Chael (1991). The seismograms were filtered with a 4-pole Butterworth causal filter and backazimuths calculated over a specific time span. Errors were found by subtracting the azimuth determined from the PDE locations from the calculated azimuths. The PDE locations are regarded to be accurate to 10 to 16 $\mathrm{km}$, so the reference backazimuths should be a reliable standard with which to compare the three-component backazi-muth estimate. Different time spans, filter and methods were used to calculate backazimuths (Table 2). Methods used were Magotra et al. (1987) and Roberts et al. (1989). They use different constraints on the nature of the polarization of P. arrivals and background noise. Estimates are close for strongly polarized signals. Backazimuth calculations were made for 70 of the 91 events in the data base. The best results 


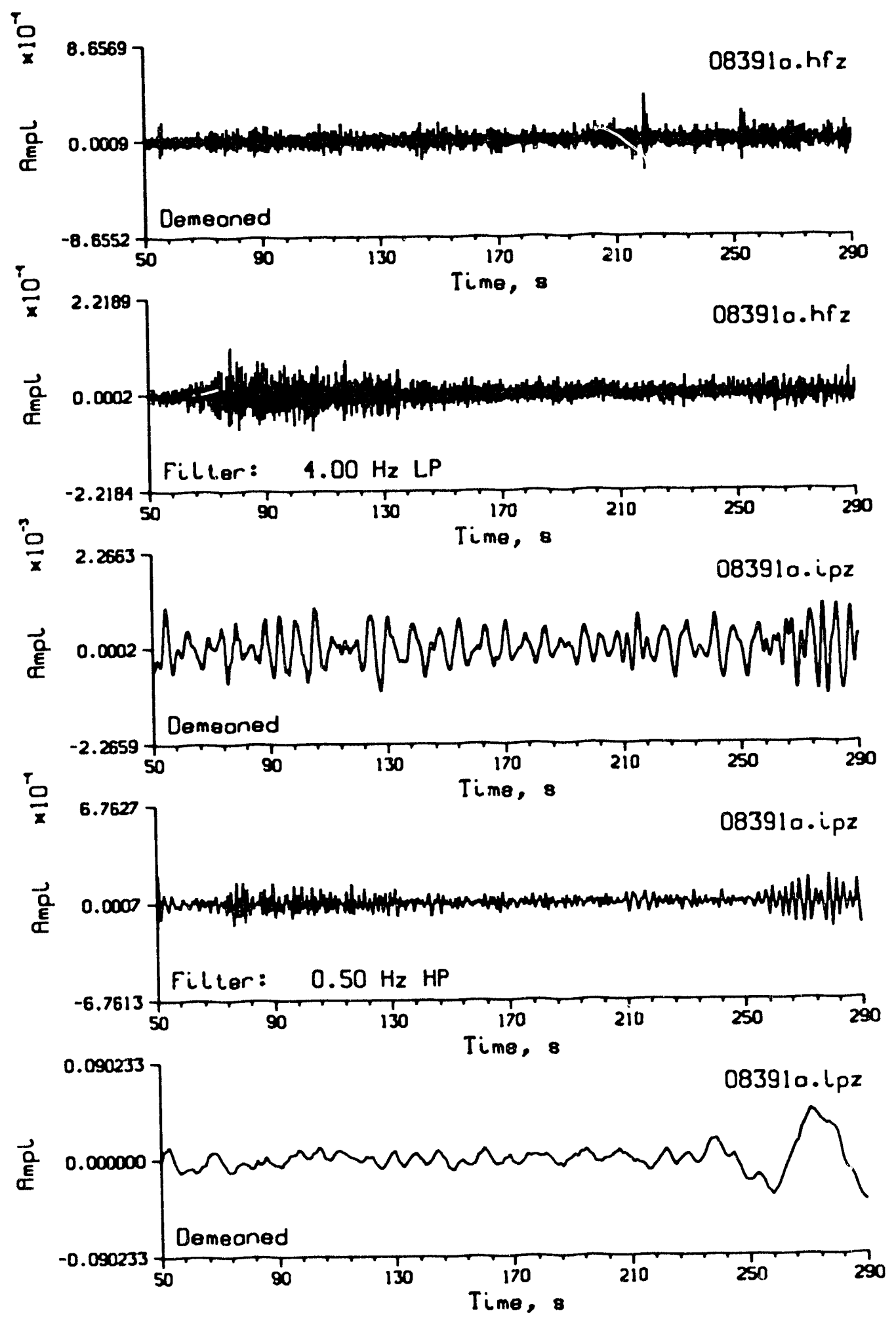

Figure 13. Traces of $a m_{b}=4.3$ carthquake occurring $1200 \mathrm{~km}$ west of PSRF show how filtering of the $\mathrm{HF}^{\mathrm{N}}$ band can be important when detecting events. This event was first detected by finding the $\mathrm{L}_{\mathrm{g}}$ arrival on the L.P hand. 


\section{WUS mb vs NEIS mb}

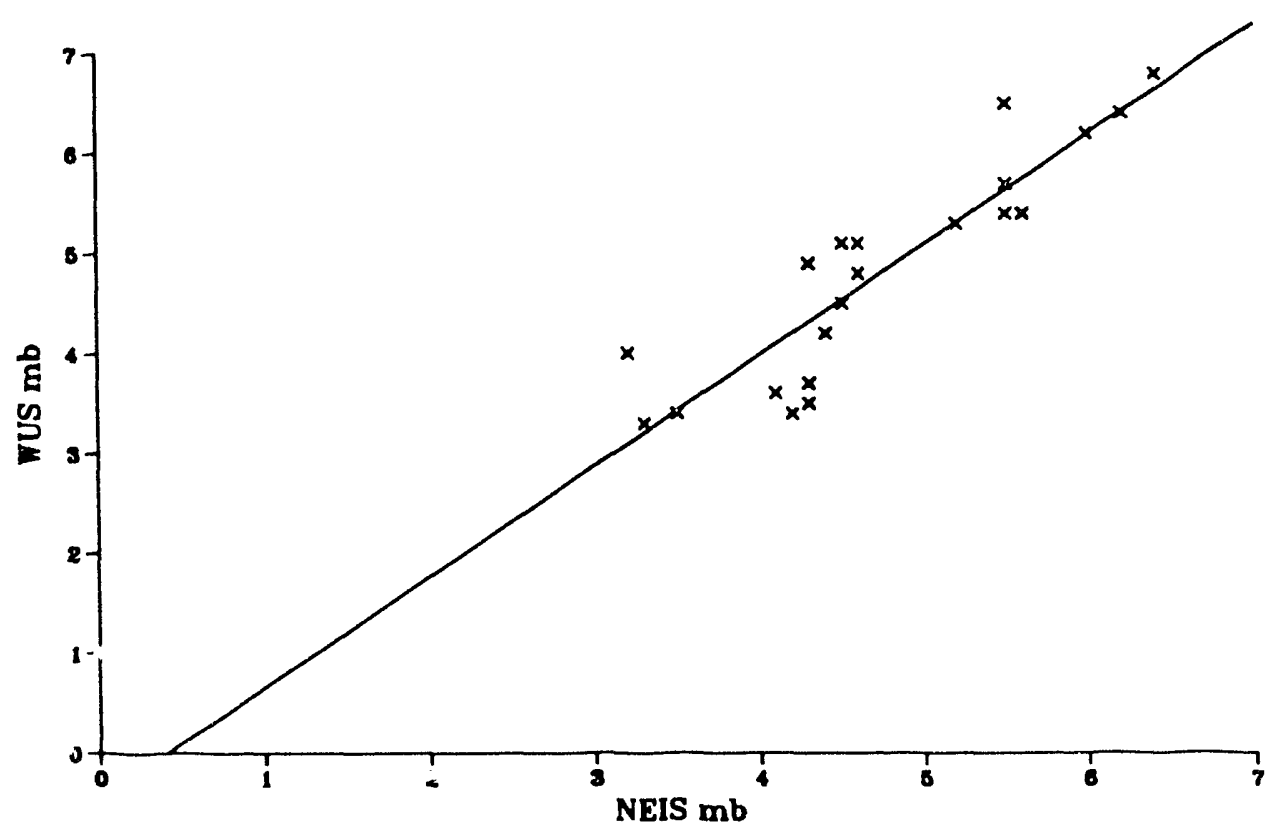

Figure 14. NEIS $m_{b}$ magnitudes compared to magnitudes calculated using Evernden's WUS magnitude calculation. The least-squares fit has a slope of 1.1 .

occur wher, the data is filtered at low frequencies $(0.5-2.0 \mathrm{~Hz})$ and calculated over an eight second time window. Results using both methods are in Figure 15. The Magotra et al. (1987) method gives azimuth errors that range in absolute value from $1.6^{\circ}$ to $175.1^{\circ}$. The mean or bias is $5.0^{\circ}$ and the precision is $38.0^{\circ}$. The precision and bias decrease slightly using the method by Roberts et al. (1989); $4.2^{\circ}$ and $37.1^{\circ}$ respectively. The absolute values of the errors range from $0.2^{\circ}$ to $162.2^{\circ}$. If another station is used aiong with DSVS at PSRF to determine locations then the ambiguity in direction if the error is greater than $90^{\circ}$ can be resolved. If errors are rotated to be within $\pm 90^{\circ}$, the mean error increases but the precision is better. The precision improves to $24^{\circ}$ using Magotra et al (1987), and is $27.3^{\circ}$ using the method by Roberts et al. (1989). We compared the backazin uth estimation capabilities of DSVS to the RSTN stations in Walck and Chael (1991) and results from the NORESS (Bame et al, 1990) and ARCESS (Carr, in prep.) arrays in Norway (Table 3). Most of the RSTN stations and both of the arrays have better precision than DSVS at PSRF. The site with the poorest precision is RSSD which Walck and Chael attribute to dis

Table 2. Filters, time spans and methods used to calculate backazimuths

Eilters

$0.5-2.0 \mathrm{~Hz}$

$0.5-4.0 \mathrm{~Hz}$

0.5-8.0 Hz

$2.0-4.0 \mathrm{~Hz}$
Time spans

2 seconds

5 seconds

8 seconds

\section{Methods}

Magotra et al. (1987)

Roberts et al. (1989) 

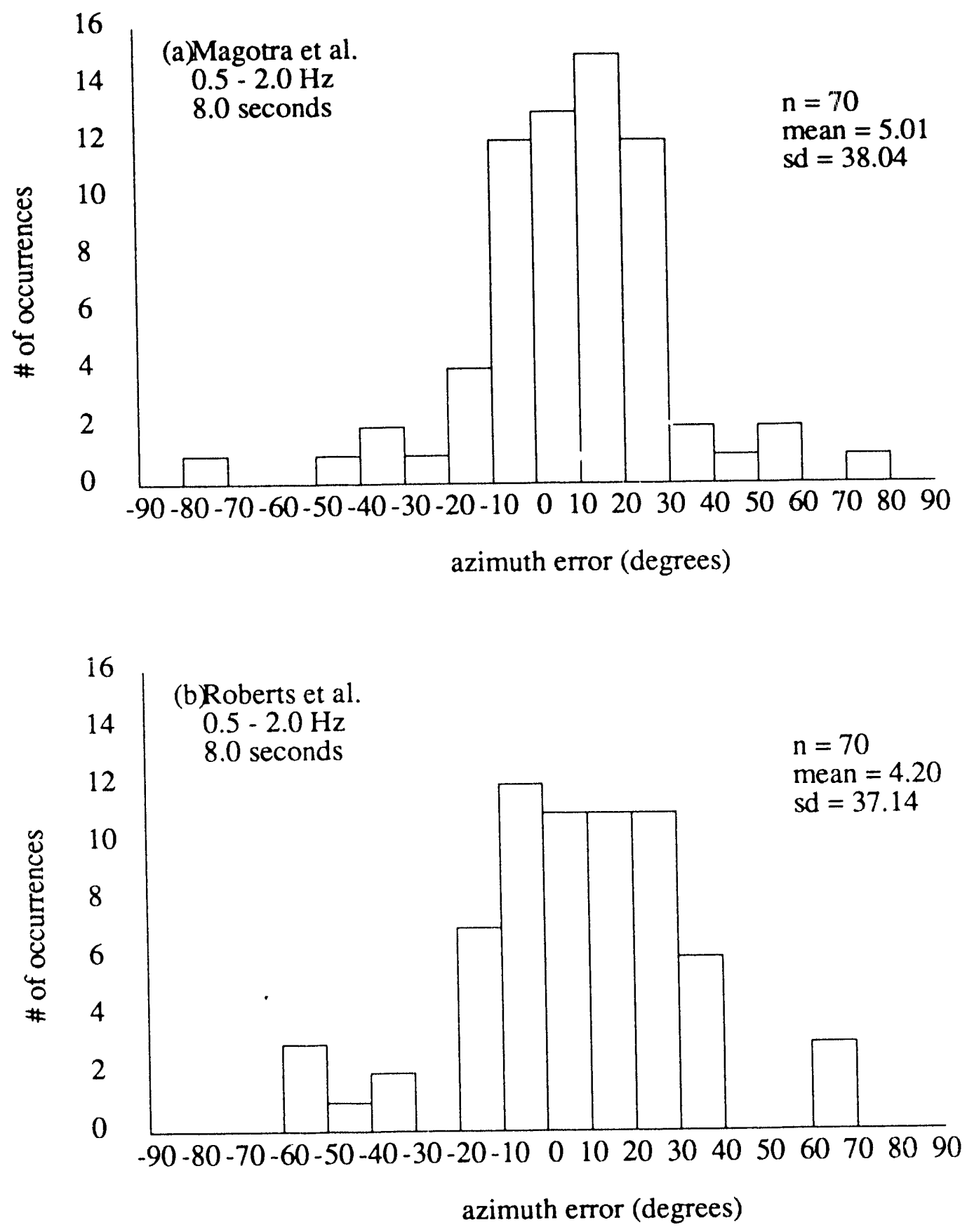

Figure 15. (a) The range of errors in backazimuth for 70 events around PSRF using the method of Magotra et al. (1987), 0.5-2.0 Hz filter and 8 second time window. The mean is $5.01^{\circ}$ and the standard deviation is $38.04^{\circ}$. (b) The range of errors in backazimuth for 70 events around PSRF using the method of Roberts et al. (1989), $0.5-2.0 \mathrm{~Hz}$ filter and 8 second time window. The mean is $4.20^{\circ}$ and the standard deviation is $37.14^{\circ}$.

torting of the incoming seismic energy at the site. Looking closer at DSVS at PSRF, we found that backazimuth errors are larger for events with signal-to-noise ratios less than 10 , and we also saw an azimuthal dependence in error. Events located NE of PSRF (azimuths 
Table 3. Precision of backazimuth estimation

$\begin{array}{llll}\text { Station } & \text { Precision } & \text { Station } & \text { Precision } \\ \text { DSVS } & 24.0^{\circ} & \text { RSCP } & 13.5^{\circ} \\ \text { RSNY } & 10.6^{\circ} & \text { NORESS } & 11.1^{\circ} \\ \text { RSON } & 21.3^{\circ} & \text { ARCESS } & 16.9^{\circ} \\ \text { RSSD } & 27.6^{\circ} & & \end{array}$

less than $112^{\circ}$ ) have an average mean error of $12.5^{\circ}$. The average mean error was $29.8^{\circ}$ for events located at azimuths over $290^{\circ}$. Because of the differences in backazimuth error with SNR and azimuth, we believe the poor precision achieved when calculating backazimuths with DSVS at PSRF is due to site characteristics, not the instrumentation.

\section{Overlapping Frequencies}

The overlapping frequency span in the IP band and LP band were compared by low pass filtering the IP band at frequencies under $0.06 \mathrm{~Hz}$. Filtered IP traces and LP traces are shown in Figures 16 and 17. The event in Figure 16 is a nuclear explosion from NTS. The characteristic long period signal is seen on both the LP band and the filtered IP band. An earthquake occurring $625 \mathrm{~km} \mathrm{SSW}$ of PSRF is shown in Figure 17. The $\mathrm{L}_{\mathrm{g}}$ phase arrives at around $160 \mathrm{sec}$ where the high frequency energy component starts. The two bands are not identical for either event, because of the affects of filtering, the differences in the sample rate and for the NTS event, gain ranging on the LP band. However, the traces are very similar, and no information is really lost by filtering the IP band. The response of the two bands would be the same if inverse filtering was applied to the IP band and then the data filtered by the LP band response. It was more difficult to compare the overlapping frequency span in the HF and IP bands. When both bands are bandpassed between 0.5 and $2.5 \mathrm{~Hz}$, the HF band has less low frequency energy because of the sharp roll off at $0.5 \mathrm{~Hz}$ used to shape the HF band. The response of the two bands would be the same however, if inverse filtering was applied to the IP band and the data filtered by the $\mathrm{HF}$ band response.

\section{Importance of Broadband Recording}

The frequency response of DSVS at PSRF was studied by determining the frequency at which the P-wave signal went into the background noise on HFZ for each event. The majority of events did not have energy at frequencies over $20 \mathrm{~Hz}$. When the frequency at which the signal goes into the background noise is plotted against distance (Figure 18) we see an exponential decay of frequency with distance. Except for large magnitude events $\left(m_{b}>6.0\right)$, we don't see energy over $30 \mathrm{~Hz}$ unless the distance is less than $330 \mathrm{~km}$. There also appears to be a difference in frequency response with azimuth (Figure 19). Events to the east of PSRF are more likely to have energy at frequencies over $20 \mathrm{~Hz}$ than events west of PSRF. The reason for this is the difference in the tectonic regimes that are east and west of PSRF. The eastern United States (EUS) is a stable shield region compared to the tectonically active WUS. The complex geology west of PSRF attenuates the higher frequencies at a faster rate. Another area where frequency attenuation has been studied 

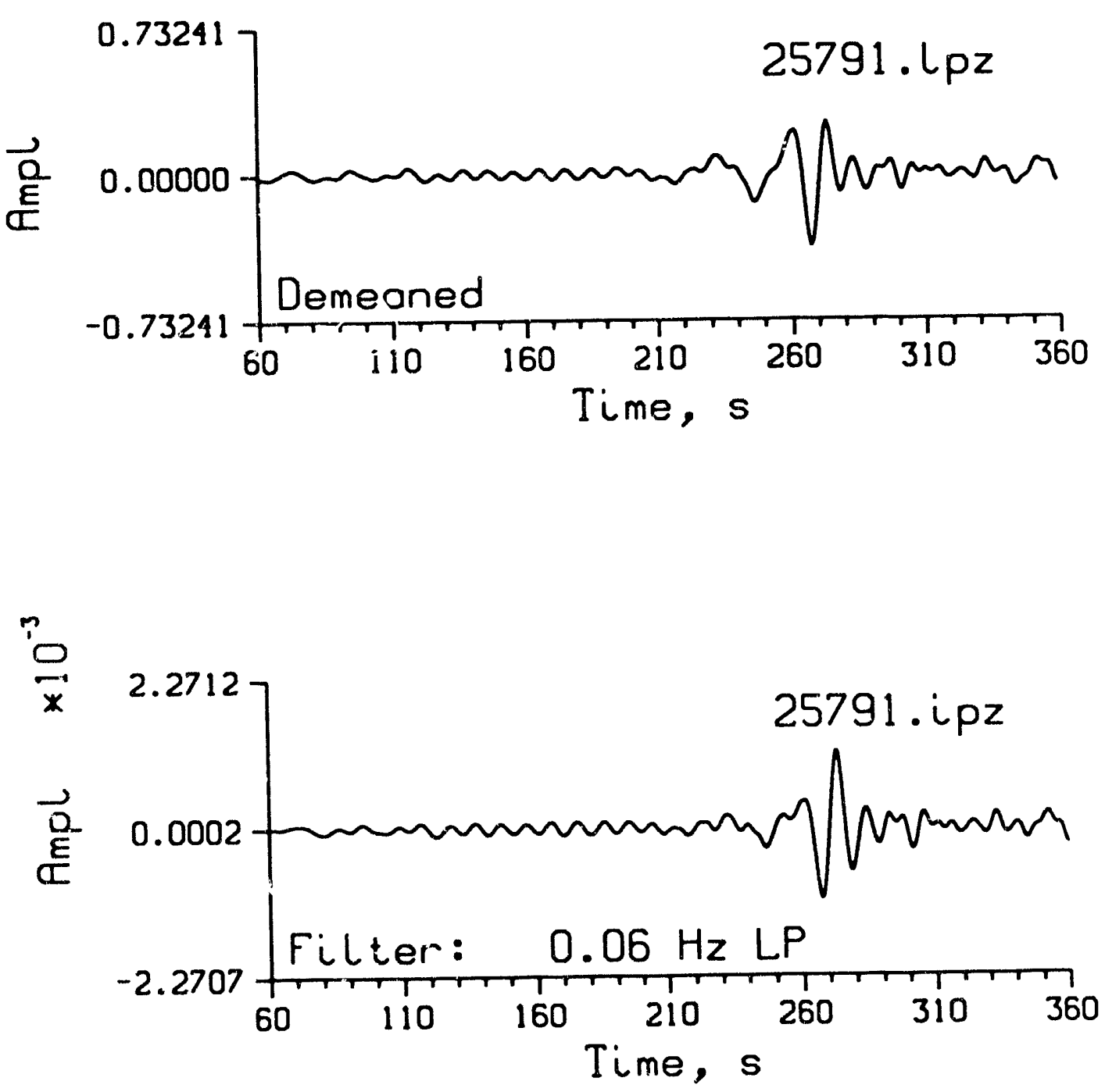

Figure 16. A NTS nuclear explosion recorded on DSVS at PSRF on the LP band and low pass filtered (0.06 Hi.) IP band. 

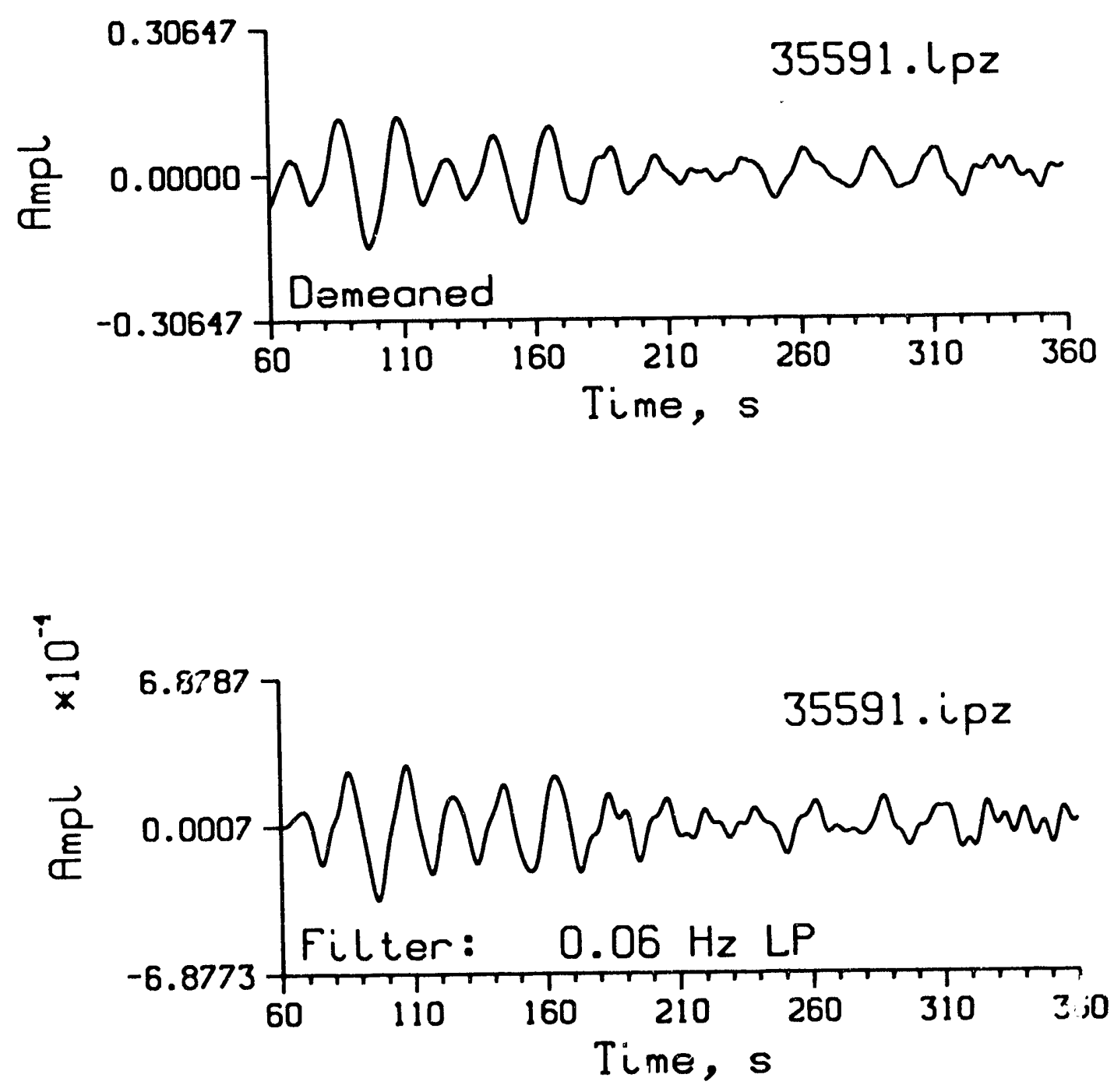

Figure 17. An earthquake occurring $625 \mathrm{~km}$ SSW of PSRF recorded on the LP band and low pass filtered $(0.06 \mathrm{~Hz})$ IP band. 


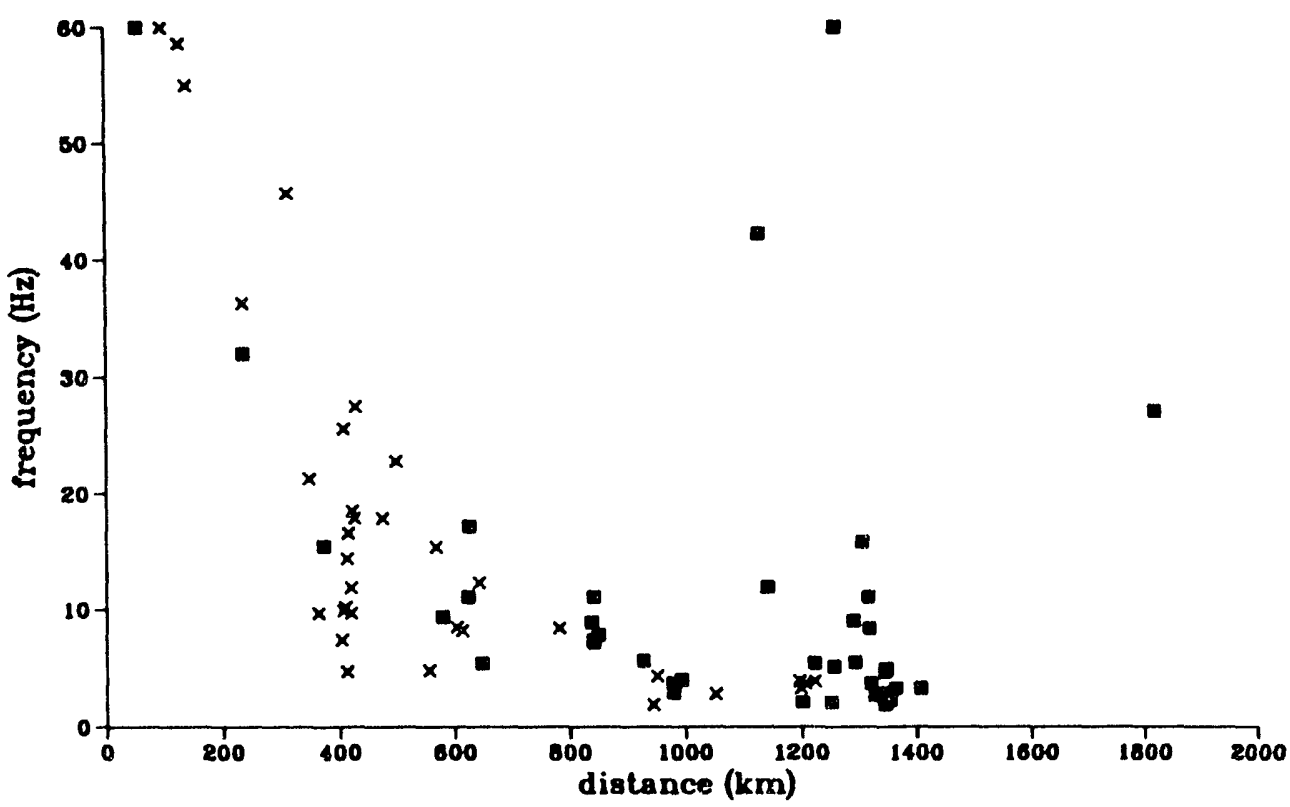

Figure 18. The frequency where the signal goes into the background noise on HFZ compared to the distance from the event location to PSRF $\left(\mathrm{ml}(\mathrm{x})\right.$ and $\left.\mathrm{m}_{\mathrm{b}}(\mathrm{box})\right)$. There is an exponential decay in frequency with distance except for a few large magnitude events. The event at $1262 \mathrm{~km}$ with a frequency of $60 \mathrm{~Hz}$ is a $6.0 \mathrm{~m}_{b}$ earthquake off the northern California coast. The event at $1130 \mathrm{~km}$ with a frequency of $42 \mathrm{~Hz}$ is a $6.2 \mathrm{~m}_{b}$ carthquake near Yucca Valley California. The event at $1820 \mathrm{~km}$ with a frequency of $27 \mathrm{~Hz}$ is a $4.4 \mathrm{mb}_{\mathrm{b}}$ earthquake from the New Madrid fault zone.

was in southern Norway (Bame, 1989). The magnitude range of the events used in the Norwegian study are local magnitudes between 0.2 and 3.5. The signals have energies out to $30 \mathrm{~Hz}$ for events out to distances of $1400 \mathrm{~km}$. Energies over $30 \mathrm{~Hz}$ are not seen unless the event occurs less than $600 \mathrm{~km}$ from the seismometer. In Norway, another stable continental shield, we see that smaller magnitude events have higher energy content than events in the mid-continent and WUS at similar distances.

Even in a good area for high frequency propagation such as Norway, frequencies over $30 \mathrm{~Hz}$ are not valuable unless the event is close to the seismometer. The local high frequency noise can obscure the signal of events with small magnitudes and at large distances. Frequencies out to $50 \mathrm{~Hz}$ were implemented in DSVS because it was thought that earthquakes and nuclear explosions could be discriminated using frequencies out to 100 Hz. In a study by Bame-Carr (1992) looking at known earthquakes and chemical explosions in Norway recorded to $50 \mathrm{~Hz}$, there was no difference between the two. At NTS, Chael (1988) found that spectral differences between earthquakes and nuclear explosions could be seen at frequencies from 10 to $30 \mathrm{~Hz}$. At DSVS, events in the WUS don't have energy over $20 \mathrm{~Hz}$ unless it is a large magnitude event. The nuclear explosions from NTS in the database only have energy out to between 7 and $10 \mathrm{~Hz}$ at PSRF, so any attempts at discrimination at frequencies at 15 to $30 \mathrm{~Hz}$ cannot be done. 


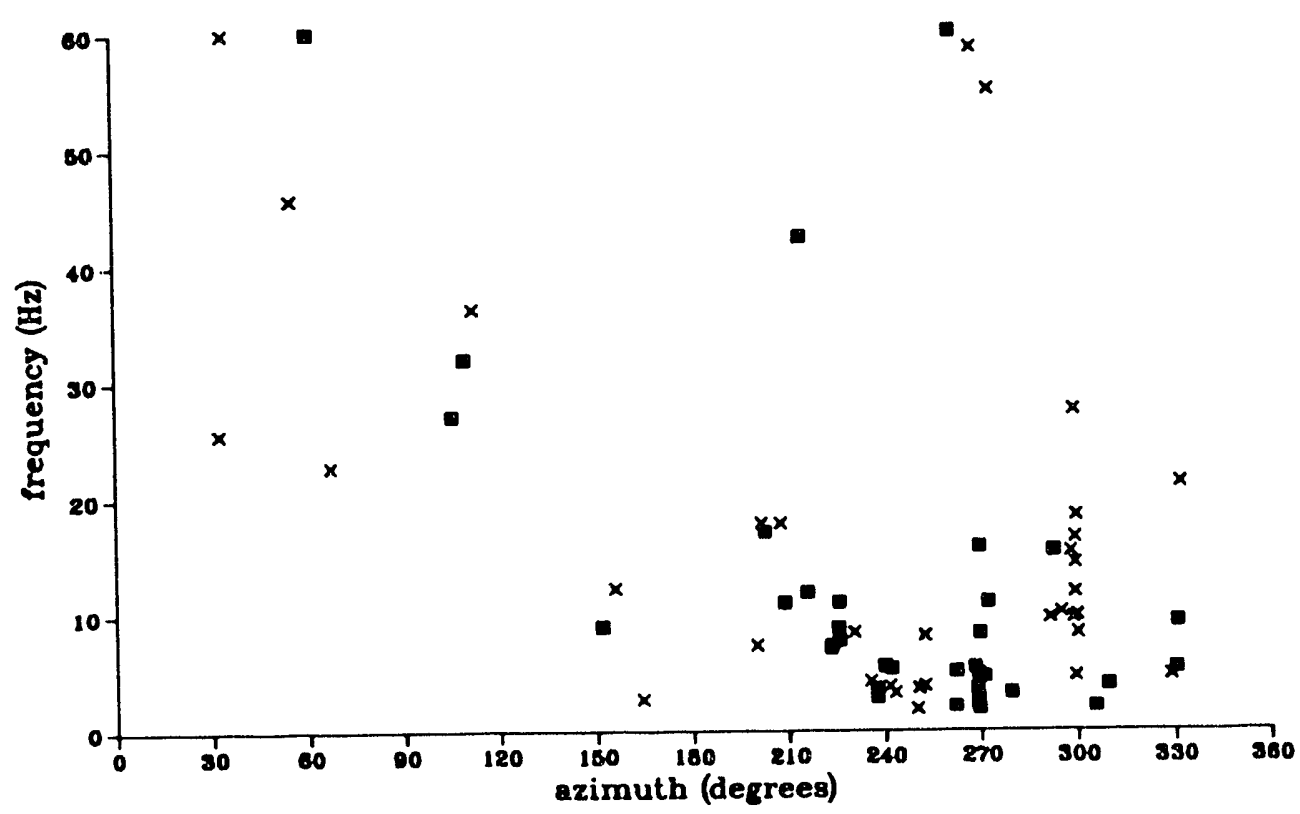

Figure 19. The frequency where the signal goes into the background noise on HFZ compared to the azimuth of the event location to PSRF $\left(\mathrm{ml}(\mathrm{x})\right.$ and $\left.\mathrm{m}_{\mathrm{b}}(\mathrm{box})\right)$. Except for $\mathrm{m}_{\mathrm{b}}=6.2$ and $\mathrm{m}_{\mathrm{b}}=6.0$ earthquakes and two events within $150 \mathrm{~km}$ west of PSRF, events to the east of PSRF have higher trequency energy than events to the west of PSRF.

Looking at the overlapping frequency spans and high frequency attenuation suggests that only two frequency bands are necessary for DSVS. An HF band that covers frequencies between 0.5 and $30 \mathrm{~Hz}$ and the IP band that covers frequencies between 0.01 and $2.5 \mathrm{~Hz}$. And to facilitate detection of events in a broad frequency band, a sophisticated detection and location package needs to be implemented at the analysis center. Automated processing techniques should be applied before human analysis.

\section{State of Health (SOH)}

The state of health ( $\mathrm{SOH}$ ) information ensures the quality of the data before it is analyzed. It is divided into thirteen sections (Table 4). We looked at SOH to determine if all the information being collected is important and necessary and if any different information should be added.

SOH was evaluated in a number of ways. Daily checks of the SOH information were used to determine the status of the instrumentation. Currents and voltages were checked, along with temperatures of both equipment and vault areas. Calibrations of the seismometers were run approximately every 150 minutes. Data quality was checked by looking at the verification checksum. SOH information was also used for diagnostic purposes in the field. When the system would go down, things like the TEG voltages, battery 
Table 4. State of Health Information

\section{frame description \\ SITE MONITORS}

$\infty$

01

02

03

04

05

06

07

08

09

10

11

12

\section{RECV/XMIT MONITORS}

25 HPA temperature

$26 \mathrm{RT}+12$

27 RT -15

$28 \quad \mathrm{RT}+5$

$29 \quad \mathrm{RT}+15$

30

31 receiver signal level

HPA power

phase crror

RT module current

antenna tilt

C.PLOLOCK

L-PLOLOCK

MODFAULT

DMODCARLOCK

BITSYNC

HPAPATH

DECODFAULT

DEMODFAULT frame description

\section{TAPE MONITORS}

50 tempcrature

51 tape $1+12$ supply voltage

52 tape $2+12$ supply voltage

54 tape $1+5$ supply voltage

55 tape $2+5$ supply voltage

57 tape recorder current

58 RT HPA. sclect

59 RT HPA on

60 recorder 1 power

61 recorder 2 power

66 recorder 1 full

67 recorder 2 full

70 recorder 1 error

71 recorder 2 error

$74 \%$ tape left in recorder

UPHOLE MONITORS

$85+5$ supply voltage

$86+5$ return voltage

$87+12$ supply voltage

$88+12$ return voltage

$89-12$ supply voltage

90 module current

91 temperature

92 delay board malfunction

93 delay board reset

94 delay memory error

95 SOH board malfunction

96 CPU reset

97 any comm. board reset

98 GPS satcllite lock crror

\section{DHL MONITORS}

115 DHL chan. 1 malfunction

116 DHL chan. 1 comm. line error

117 DHL chan. 2 malfunction

118 DHL chan. 2 comm. line error COMMAND MONITORS

140 command echo byte 1

141 command echo byte 2

142 command echo byte 3

143 command echo bytc 4

\section{SEISMIC SOH}

$150 \quad \mathrm{Z}$ mass position 
Table 4. State of Health Information (cont.)

\begin{tabular}{|c|c|c|c|}
\hline frame & description & frame & description \\
\hline 151 & $\mathrm{~N}$ mass position & 201 & EEPROM \& auth. keys erased \\
\hline 152 & E mass position & 202 & power failure recovery \\
\hline 153 & calibration signal & \multicolumn{2}{|c|}{ CONTROL SOH } \\
\hline 154 & pressure & 203 & verify byte ptr. VBALO \\
\hline 155 & temperature & 204 & verify byte ptr. VBAHI \\
\hline 156 & carrier & 205 & verify byte ptr. VBBANK \\
\hline 157 & carricr & 206 & timing offset \\
\hline 158 & G. clip & 207 & timing DAC control \\
\hline 159 & $\mathrm{ZA}$ voltage & 208 & slave response byte SRB0 \\
\hline 160 & NA voltage & 209 & slave response byte SRB1 \\
\hline 161 & EA voltage & 210 & slave response byte SRB2 \\
\hline 162 & $\mathrm{ZC}$ voltage & 211 & slave response byte SRB3 \\
\hline 163 & NC voltage & 212 & mode mod. counter \\
\hline 164 & EC voltage & 213 & array element number \\
\hline \multirow[t]{2}{*}{165} & auxiliary voltage & 214 & verify checksum \\
\hline & DHL SOH & 215 & last msg. received MSBGT0 \\
\hline 170 & -15 supply voltage & 216 & last msg. reccived MSBGT1 \\
\hline 171 & +15 supply voltage & 217 & last msg. received MSBGT2 \\
\hline 172 & +5 supply voltage & 218 & last msg. received MSBGT3 \\
\hline 173 & temperature & 219 & last msg. received MSBGT4 \\
\hline 174 & pressure & 220 & last msg. received MSBGT5 \\
\hline 175 & relative humidity & 221 & last updated SOH \\
\hline 176 & +5 return voltage & \multicolumn{2}{|r|}{ HRD SOH } \\
\hline 177 & +15 return voltage & 225 & HF Z sync \\
\hline 178 & batuery & 226 & HF Z status \\
\hline 179 & osc. control voltage & 227 & HF N sync \\
\hline 180 & tamper voltage & 228 & HF N status \\
\hline \multicolumn{2}{|c|}{ TIMING STATUS REGISTER } & 229 & HF E sync \\
\hline 185 & slave / master mode & 230 & HF E status \\
\hline 186 & tuming msg. transmit enable & 231 & IP Z sync \\
\hline 187 & update / routine msg. type & 232 & IP Z status \\
\hline 188 & slave time error $<3 \mathrm{~ms}$ & 233 & IP N sync \\
\hline 189 & update timing msg. ok & 234 & IP N status \\
\hline 190 & jamset this frame & 235 & IP E sync \\
\hline 191 & master verify error & 236 & IP E status \\
\hline 192 & timing asynchronous & \multicolumn{2}{|c|}{ MISCELLANEOUS } \\
\hline \multicolumn{2}{|c|}{ OPERATING STATUS REG. } & 240 & spare \\
\hline 195 & UHL/DHL comm. link ok & 241 & fixed data mode flag \\
\hline 196 & operate/install mode & 242 & AUTH test mode flag \\
\hline 197 & system reset flag & 247 & HF HRD clip detect \\
\hline 198 & system reset indicator & 248 & IP HRD clip detect \\
\hline 199 & SDLC error flag & 249 & data acquisition $\mathrm{SOH}$ \\
\hline 200 & tamper detect & \multicolumn{2}{|c|}{ repeat 150 through 249 for 2 nd boreho } \\
\hline
\end{tabular}


voltages HPA power and receiver signal levcls would be checked to determine where the problem occurred.

The time flag also part of the SOH information. The timing of DSVS at PSRF was good except for a period from September 10, 1991 through February 18, 1992 when the time was anywhere from \pm 30 seconds off. This was due to problems in the GPS satellite hardware and was corrected by implementing new software from Motorola. After February 1992 there were occasional problems with the time lock on the satellite, but they were fixed by the end of 1992 .

The information collected in the SOH was valuable and useful in monitoring the system and keeping it running. The weather station and its SOH values was especially important in looking at the background noise. One area where there was not enough information was on the communications module. Sometimes there were difficulties in retrieving data from back-up tapes, and there was not enough information to determine why there was a problem. Two things would increase the usefulness of the $\mathrm{SOH}$ information; a real-time monitor and a paperless log of system problems. Both could be accomplished with a "semi" expert system that would monitor SOH in real time, warn the operator of problems and log the most probable reason for the problem (i.e. TEG voltage down, RT problem, etc.)

\section{Operational Characteristics}

Since funds were not available to evaluate this system in an operational mode similar to the evaluation of the National Seismic Stations (NSS) in the Regional Seismic Test Network (RSTN), no real statistics were derived on operational performance. We would expect the performance to be similar to that of the NSS since the same design principles were followed. Statistics from the RSTN availability showed a data availability of 0.9992 and a mean time between failures (MTBF) of 2.08 years (Harrer, 1989). We do not imply that these statistics apply to the DSVS, only that the comparisons should be good.

\section{References}

Bame, D., "Propagation of high frequencies in Scandinavia", SAND88-1047, 1989.

Bame, D.A., M. C. Walck and K. L. Hiebert-Dodd, "Azimuth estimation capabilities of the NORESS regional seismic array”, Bull. Seism. Soc. Am., 80, 1999-2015, 1990.

Bame-Carr, D., "Discrimination using spectral slopes at frequencies up to 50) Hz", Bull. Seism. Soc. Am., 82, 337-351, 1992.

Basham, P. W. and K. Whitman, "Microseismic noise on Canadian seismograph records in 1962 and station capabilities", Pub. Dom. Obs. 32, 123-135, 1966.

Bungum, H., E. Rygg and L. Bruland, "Short period seismic noise structure at the Norwegian Seismic Array", Bull. Seism. Soc. Am., 61, 357-373, 1971. 
Carr, D. B., "Azimuth estimation capabilities of the ARCESS regional seismic array", Bull, Seism. Soc. Am., (submitted for publication).

Chael, E. P., "Spectral discrimination of NTS explosions and earthquakes in the southwestern United States using high-frequency regional data", Geophys. Res. Lett., $15,625-628,1988$.

"Deployable Seismic Verification Plan", DSVS Working Group, USDOE/NV, January 30, 1987.

Der, Z.A., A. O'Donnell, T. W. McElfresh, R. Jutila, J. A. Burnetti, M. Marshall, M. Silk and E. Gordon, "A study of seismic wave propagation at regional distances in five areas of the world", VSC-TR-82-14, 211pp, 1982.

Evernden, J. F., "Magnitude determination at regional and near regional distances in the United States", Bull. Seism. Soc. Am., 57, 591-693, 1967.

Fyen, J., "NORESS noise spectral studies and noise level characteristics" in NORSAR Semiannual Technical Summary 1 October 1986 - 31 March 1987, Scientific Report 2-86/87, 46-58, 1987.

Harrer, S. J., "Regional Seismic Test Network (RSTN) Operations Final Report", EGG10617-6062, 92pp, 1989.

Magotra, N., N. Ahmed, and E. Chael, "Seismic event detection and source location using single station (three-component) data”, Bull. Seism. Soc. Am., 77, 958-971, 1987.

Molnar, P. and J. Oliver, "Lateral variations of attenuation in the upper mantle and discontinuities in the lithosphere", J. Geophys. Res., 74, 2649-2682, 1969.

Ringdal, F. and H. Bungum, "Noise level variation at NORSAR and its effect on detectability", Bull. Seism. Soc. Am., 67, 479-492, 1977.

Roberts, R. G., A. Christoffersson and F. Cassidy, "Real-time event detection, phase identification and source location estimation using single-station three-component seismic data", Geophys. J, 97, 471-480, 1989.

Smart, E. and H. Sproules, "Detection of regional phases" in Preliminary Results of the VELA Seismological Center Research in FY80, AFTAC-TR-80-37, 85-91, 1980.

Taylor, S. R., 1981, "Properties of ambient seismic noise and summary of noise spectra in the vicinity of RSTN sites", UCID-18928.

Walck, M. C. and E. P. Chael, "Optimal backazimuth estimation for 3-component recordings of regional seismic events", Bull. Seism. Soc. Am., 81, 643-666, 1991. 
Distribution:

US Department of Energy

Office of International Security Affairs

Attn: M. Koontz
L. Casey
D. Breding

Forrestal Bldg. IS-20

1000 Independence Ave. SW

Washington, DC 20585

Air Force Technical Applications Center

Attn: F. Pilotte (TT)

Lt. Col. M. Winchester (TTS)

Cpt. S. Doran (TTS)

Patrick AFB, FL 32925

Pinedale Seismic Research Facility

AFTAC Dept 489

Attn: D. Benedetti

Boulder, WY 82923

Advanced Research Projects Agency

Attn: R. Alewine

A. Ryall

Nuclear Monitoring Research Office

1400 Wilson Blvd.

Arlington, VA 22209

Lawrence Livermore National Laboratory

Attn: M. Denny

F. Followell

W. Hannon

D. Harben

K. Nakanishi

J. Zucca

P.O. Box 808

Livermore, CA 94550
Los Alamos National Laboratory

Attn: C. Newton MS335

S. Taylor MS335

T. Weaver

P.O. Box 1663

Los Alamos, NM 87545

US Dept. of Energy Nevada Field Office Attn: J. O Donnell

P.O. Box 98578

Las Vegas, NV 89193-8518

USGS-Albuquerque Seismological Lab.

Attn: B. Hutt

$$
\text { J. Peterson }
$$

Bldg 10002

Kirtland ARB 87115

Center for Seismic Studies

Attn: G. Gustoffson

R. Blandford

Suite 1450

1300 North 17th Street

Arlington, VA 22209

Teledyne Geotech

Attn: O. D. Starkey

3401 Shiloh Rd.

Garland, TX 75040

EG\&G Energy Measurements Inc.

Attn: J. Tsitouras MS570/D-12

P.O. Box 1912

Las Vegas, NV 89125

RSN

Attn: S. Thompson

P.O. Box Y5487

Las Vegas, NV 89193-5487 
IRIS Headquarters

Attn: Rhett Butler

1616 North Fort Myer Dr. Suite 1440

Arlington, VA 22209

Dr. Roger Hansen

University of Colorado

Department of Physics

Joint Seismic Program Center

Campus Box 583

Boulder, CO 80309-0390

$\begin{array}{ll}5004 & \text { P. A. Stokes } \\ 6114 & \text { M. W. Scott } \\ 6114 & \text { E. F. Roseth } \\ 6116 & \text { M. C. Walck } \\ 6116 & \text { C. J. Young } \\ 9200 & \text { T. A. Sellers } \\ 9201 & \text { T. G. Taylor } \\ 9204 & \text { L. S. Walker } \\ 9204 & \text { D. B. Shuster } \\ 9232 & \text { B. N. Malm } \\ 9236 & \text { P. B. Herrington } \\ 9236 & \text { D. R. Breding } \\ 9236 & \text { D. B. Carr (5) } \\ 9236 & \text { E. P. Chael } \\ 9236 & \text { J. P. Claassen } \\ 9236 & \text { B. H. Corbell } \\ 9236 & \text { R. P. Fleming } \\ 9236 & \text { S. J. Harrer } \\ 9236 & \text { J. W. Walkup } \\ 9311 & \text { A. J. Chabai } \\ 9311 & \text { H. D. Garbin } \\ 8523-2 & \text { Central Technical }\end{array}$

8523-2 Central Technical Files

7141 Technical Library (5)

7151 Technical Publications

7613-2 Document Processing for DOE/OSTI (10) 

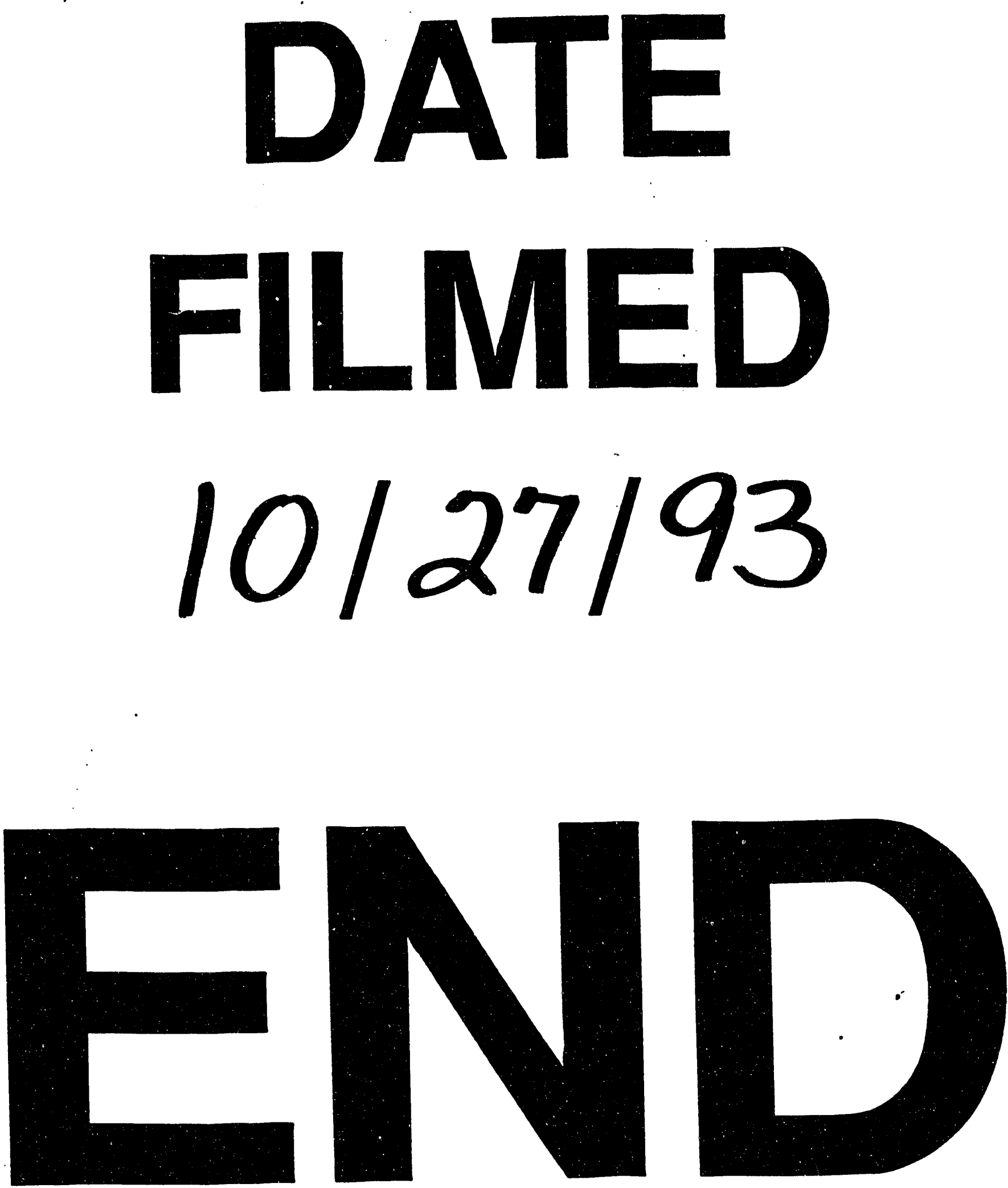


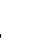

